\title{
EL VECINDARIO DE 1683: UNA FUENTE INÉDITA PARA EL ESTUDIO DE LA POBLACIÓN DE LA CORONA DE CASTILLA*
}

\author{
RAMÓN LANZA GARCÍA \\ Universidad Autónoma de Madrid ${ }^{a}$
}

\begin{abstract}
RESUMEN
La reforma fiscal de 1683 generó una documentación de gran interés demográfico todavía inédita que este artículo presenta y evalúa con el fin de conocer la evolución de la población de Castilla en una época que hasta ahora carecía de datos fidedignos. La verosimilitud del Vecindario de 1683 se comprueba doblemente, primero con el test de las tasas de natalidad y luego comparando el crecimiento de la población con el de los bautismos. El resultado confirma que el declive de 1591-1631 no se había recuperado todavía en 1683 y que el crecimiento posterior fue más rápido en 1683-1752 que en 1752-1787.
\end{abstract}

Palabras clave: Castilla, población, vecindario, crecimiento demográfico

\footnotetext{
* Este trabajo ha sido realizado en el marco del Proyecto de Investigación «Fiscalidad, economía y política en Castilla durante los reinados de Felipe IV y Carlos II». Ministerio de Ciencia y Tecnología-FEDER, BHA 2002-01942. A la siempre amable y eficaz Isabel Aguirre agradezco profundamente la paciencia con que me ha atendido durante las estancias en el Archivo General de Simancas, haciendo el trabajo tan grato como provechoso. También me complace expresar mi agradecimiento a Javier Vela Santamaría y a Enrique Llopis Agelán por las referencias que me proporcionaron, y a José Ignacio Andrés Ucendo, Luis María Bilbao, Emiliano Fernández de Pinedo, José Ignacio Fortea Pérez, Juan Eloy Gelabert González, Alberto Marcos Martín, Santiago Piquero y los dos evaluadores anónimos por los útiles comentarios que realizaron a una primera versión de este texto.

a Departamento de Análisis Económico: Teoría Económica e Historia Económica, Facultad de Económicas, 28049 Madrid. ramon.lanza@uam.es
} 


\begin{abstract}
The fiscal reform of 1683 originated a documentation of great demographic value that has not yet been published. This paper presents and evaluates the new source in order to know the evolution of Castilian population in a period without credible data until now. The Vecindario of 1683 is verified twice in the study, firstly by the birth rate and secondly by comparing the population growth with that of baptisms. The result demonstrated that the decline of 1591-1631 had not yet been recovered in 1683 and that the subsequent growth was faster in 1683-1752 than in 1752-1787.
\end{abstract}

Keywords: Castile, population, household censuses, demographic growth JEL Classification: N33, J11

La acción del Estado moderno precisaba, como bien es sabido y es natural en cualquier organismo político, una buena información. La ávida necesidad de conocer el número de contribuyentes y de hombres de armas explica la abundancia de los recuentos de población que se realizaron en la España moderna, algunos de los cuales permanecen todavía inéditos. La mayoría por no decir todos los vecindarios anteriores al censo de Aranda de 1768 fueron elaborados con alguna finalidad fiscal, aunque no por eso pierden interés para los estudios demográficos. Los vecindarios de la Corona de Castilla de 1528 y 1591 fueron realizados con el fin de proceder al repartimiento, en el primer caso, del servicio ordinario y extraordinario y, en el segundo, del nuevo servicio de millones, mientras que las tres famosas series de averiguaciones de alcabalas ordenadas por Felipe II en 1561, 1584 y 1595 preveían la confección de padrones nominales para conocer la capacidad contributiva de la población.

Aunque el siglo XVII no es una excepción en este panorama, pues abunda en recuentos de varias clases, la información que ofrecen ha sido en general descalificada por incompleta o defectuosa, ya que faltan localidades, no incluyen a los exentos o simplemente ocultan la verdad. Sin embargo, las deficiencias de la mayoría de estos vecindarios no pueden ser atribuidas a una supuesta relajación de la burocracia fiscal y administrativa de los Austria menores, ya que los medios a disposición de los Consejos de Castilla y de Hacienda no faltaron y si acaso fueron en aumento ${ }^{1}$. Es cierto que a veces, como a la hora de recaudar el donativo de 1635 , algunos comisarios reales no cumplieron las instrucciones que habían recibido para averiguar el número de vecinos y quiénes podían hacer algún ofrecimiento al Rey y por qué cantidad ${ }^{2}$. En otras ocasiones la naturaleza de las contri-

\footnotetext{
${ }^{1}$ Domínguez Ortiz (1992, pp. 57-58), y López-Salazar (1981, p. 183).

${ }^{2}$ Sí al menos en los Obispados de Badajoz, Ciudad Rodrigo, Coria y Plasencia. AGS, CG, leg. 3186, y DGT, Inv. 24, leg. 1381.
} 
buciones y los sistemas de recaudación no hacían necesario un conocimiento preciso de la población. Así, en el Vecindario de 1646, que al parecer se hizo para el repartimiento de juros, faltan numerosas localidades y en las demás las deficiencias son insalvables, salvo en raras excepciones ${ }^{3}$. El donativo del millón de oficios de 1651 incluye las relaciones de vecinos de numerosas localidades, pero no de todas, en las que faltan expresamente los privilegiados ${ }^{4}$. El vecindario de milicias de 1693 aparentemente no incluye a los exentos de este servicio como las viudas, los pobres y los privilegiados laicos y eclesiásticos, o se refiere a los varones aptos en edad militar. Por otra parte, la petrificación de los encabezamientos y la generalización del sistema de arrendamiento en la recaudación de los principales tributos como la alcabala, los cientos y los servicios de millones hicieron probablemente innecesaria la confección de nuevos vecindarios.

A pesar de todo, el interés de las autoridades por conocer el estado de la población no cesó por completo. A veces se presentaban ocasiones propicias para recabar información, como, por ejemplo, cuando se acometía algún intento de reforma fiscal. Así, el llamado Vecindario de la sal de 1631 tuvo su origen en el proyecto de sustituir los servicios de millones por un impuesto sobre el consumo de sal cuyo rendimiento se pretendía fijar de antemano mediante repartimiento o acopiamiento entre los vecinos, práctica habitual en la administración de la gabe$\mathrm{la}^{5}$. Una nueva oportunidad se presentó mediado el reinado de Carlos II cuando el Consejo de Hacienda decidió extinguir los arrendamientos de alcabalas, cientos y millones, implantar nuevos encabezamientos y ajustar la carga tributaria a la capacidad de pago de los contribuyentes. El proyecto dio pie a la elaboración de un nuevo recuento de vecinos que pensamos puede ser de gran utilidad, el Vecindario de 1683.

Pues bien, el objetivo de este artículo consiste en presentar esta fuente, evaluar su calidad y, a la vista de los resultados, proponer una línea de evolución de la población de la Corona de Castilla en la época que discurre entre 1631 y 1752 para la que no disponíamos hasta ahora de documentación fidedigna ${ }^{6}$. El primer apartado describe los antecedentes y la forma en que se ejecutó el vecindario.

\footnotetext{
${ }^{3}$ Como en las localidades de Extremadura donde se deducen tasas de natalidad aceptables, pero con grandes diferencias de fiabilidad, según Rodríguez Grajera (1990, p. 31).

${ }^{4}$ «La ciudad de Salamanca constó tener 1.030 vecinos sin las personas eclesiásticas y escolásticas y demás exemptos que hay en ella». AGS, CG, leg. 3227. El de Galicia aparece también en AGS, Inv. 24, leg. 1464, y ha sido estudiado por Fernández Cortizo (1990), quien reconoce ser un vecindario muy defectuoso.

${ }^{5}$ Fernández Cortizo (1990, pp. 103-130) para Galicia y Piquero, Fernández de Pinedo y Ojeda (1991, pp. 77-89). También Saavedra (1985, p. 68) ya había utilizado este recuento por medio de fuentes municipales de la antigua provincia de Mondoñedo.

${ }^{6}$ Kamen (1964, p. 71) y (1981, pp. 73, 92-93 y 295-296) ofrece los datos de algunas pocas localidades, pero sin advertir el carácter de vecindario general ni, por tanto, la magnitud y alcance de la encuesta.
} 
Dado que la información no se refiere a los habitantes, sino a los vecinos, será necesario dedicar unos comentarios a la cuestión del coeficiente para transformar éstos en aquéllos, tema al que se dedica el apartado segundo. En el siguiente se procede a comprobar la veracidad de los datos disponibles, que, por desgracia, no son completos. Precisamente en el cuarto epígrafe se presenta esta información, al tiempo que se ofrecen algunas posibles vías para reconstruir la población de la Corona de Castilla a mediados del reinado de Carlos II. Luego, el resultado se compara y comprueba con otras fuentes y al hilo de esta información se plantean algunas hipótesis, obviamente provisionales, acerca de la trayectoria y cronología que siguió la población castellana desde el declive a la recuperación.

\section{LA GESTACIÓN DEL VECINDARIO DE 1683}

El origen de este vecindario se encuentra en el deseo de reducir las consecuencias indeseadas del sistema de arrendamientos, que se había generalizado en la recaudación de alcabalas, cientos y millones, los principales tributos de la época, sin que la pesada carga tributaria que pagaban los contribuyentes redundara en un aumento de los ingresos líquidos de la Hacienda Real. Asimismo, el impacto gravosísimo de la baja de la moneda de vellón de 1680 sobre la capacidad contributiva de los castellanos tampoco debió de ser ajena a unos planes que, de todos modos, parece que ya estaban gestándose desde principios de ese mismo año, si no antes. La deflación supuso un aumento súbito de la carga tributaria en términos reales, hasta el punto de que numerosos pueblos fueron acumulando a partir de entonces importantes débitos fiscales, algunos arrendadores al parecer quebraron y la Hacienda Real no pudo satisfacer a sus acreedores, sobre todo a los juristas, que debieron ser sacrificados ante los apremios de los hombres de negocios. Ante este problema vital y tras varios debates, el Consejo de Hacienda acometió una reforma del sistema de recaudación y un ajuste de la carga tributaria al estado demográfico y económico de los contribuyentes. Los principios y procedimientos para la implantación del nuevo sistema fueron recogidos en la Real Cédula de 16 de diciembre de 1682. A esta siguió en el mismo mes la Real Instrucción que debían observar los superintendentes a quienes se cometió su ejecución y que en los primeros días de 1683 salieron a las provincias del reino. H. Kamen advirtió hace tiempo la importancia de esta reforma fiscal, cuyos fundamentos políticos, pormenores y principales resultados Sánchez Belén ha estudiado recientemente ${ }^{7}$.

Los Superintendentes, cada uno acompañado por un contador, un escribano $y$ un alguacil, realizaron un esfuerzo considerable en un tiempo muy breve a fin de

${ }^{7}$ Kamen (1981, pp. 573-576), y Sánchez Belén (1989) y (1996, pp. 230-231). 
reducir las rentas reales y los servicios de millones a valor fijo, a encabezamiento, ajustando los nuevos valores con «equidad» respecto a la capacidad de los contribuyentes. La consecución de ese objetivo precisaba el conocimiento de la vecindad y el estado económico de los pueblos, tarea a la que se aplicaron muy pronto y, según los indicios disponibles, con más que notable diligencia.

Don Diego de Alvarado informaba al Consejo de Hacienda desde Burgos el 12 de enero de 1683 que en la ciudad no había constancia de la vecindad porque no había costumbre de hacer padrones ni repartimiento personal, así que fue preciso convocar a los procuradores para que hicieran «sumario de todos los vecinos calle aita sin exceptuar ningunos» ${ }^{8}$. Tampoco en la ciudad de León había padrones ni acopiamientos de vecindad, pero la «común estimación» era de 3.050 vecinos según el Marqués del Castillo, Corregidor y Superintendente de la provincia, que no dejó de prevenir la vecindad de cada pueblo en los pliegos del nuevo encabezamiento ${ }^{9}$. Don Francisco de Aguirre tampoco dice cómo supo la vecindad de Salamanca, pero aseguraba conocerla con certeza. En Valladolid no había padrones porque no se distinguían estamentos para la elección de oficios y el repartimiento de contribuciones, pero el testimonio de los más ancianos sirvió a Don Pedro de Oreitia, más tarde gobernador del Consejo, para asegurar que la ciudad con sus arrabales y alquerías «se compone» de 4.000 vecinos con poca diferencia, siendo lo principal las corporaciones eclesiásticas y «demás clerecía, que es infinita» ${ }^{10}$.

No todos los superintendentes fueron tan parcos respecto a los medios de que se valieron para averiguar las vecindades, pero a tenor de los datos que refieren algunos otros parece que tomaron testimonios fidedignos como las certificaciones de repartimientos y vecindades y los exámenes directos y personales, si no de todos, de los lugares más importantes.

Tan pronto como el 24 de febrero de 1683 el Superintendente de Jaén, Don Leonardo de la Cueva Cepeda, comunicaba al Consejo que «el padrón de vecindad se ha hecho y aún no he reconocido el número de casas que hay habitables y los vecinos que comercian o si son labradores, que se ha formado con toda distinción, y en los lugares del Reino se ha comenzado a hacer la misma diligencia». El 27 de noviembre anunciaba que ya estaban formando las «relaciones de vecindad» ${ }^{11}$.

El procedimiento general parece haber sido el que exponía Don Francisco Ronquillo, Corregidor de Córdoba y Superintendente de la Provincia. El 18 de marzo de 1683 informaba al Consejo sobre los pasos que había seguido:

AGS, CJH, leg. 1447.

${ }^{9}$ AGS, CJH, leg. 1960. Sus comentarios a propósito de otras localidades de León y de Asturias son de un tenor parecido, muestra una tendencia al redondeo al tiempo que deja entrever un conocimiento cierto de la vecindad. De hecho, el test de natalidad revela el acierto de sus apreciaciones. Vid. AGS, CJH, legs. 1444 (Asturias), 1497 y 1500 (León).

${ }^{10}$ AGS, CJH, leg. 1457. Esta cifra es citada asimismo por Domínguez Ortiz (1992, p. 137), Kamen (1981, p. 73), y Gutiérrez Alonso (1989, p. 22).

${ }^{11}$ AGS, CJH, legs. 1450 y 1459. 
«Primeramente se piden los padrones de las vecindades que se mandaron hacer por el Auto General que se despachó a las Villas y con este se andan las casas y se reconoce si está bien hecho, el porte, alhajas y granos que hay en las casas, y en los más lugares la décima parte de la vecindad es de eclesiásticos» ${ }^{12}$.

Don Pedro Velluti de Haro, desde Soria, había hecho consulta sobre la dificultad que encontraba en concluir los nuevos encabezamientos rápidamente si se detenía al menos tres días en cada uno de los casi 700 lugares de la provincia. Aunque el Consejo no le eximió de la necesidad de hacer averiguación personal, ésta sólo era posible en las villas más grandes, por lo que en los demás casos debía valerse de diversos testimonios escritos. Entre los papeles que, en todo caso, solicitaba a las autoridades locales destacaban los testimonios de encabezamientos y repartimientos de cada tributo y año, así como «otro testimonio de la Vecindad que tuviere la villa o lugar, cuántos son eclesiásticos, cuántos hidalgos, cuántos hombres buenos, qué viudas, cuántos pobres de solemnidad, cuántas Iglesias y conventos, qué tratos y granjerías y cuántos de cada trato y en años pasados qué trato había y si han cesado por qué causa». En una consulta de 12 de junio de 1683 reconocía la posibilidad de engañarse respecto a la veracidad de los informes que estaba remitiendo al Consejo, pero, no obstante, afirmaba

«es verdad [...] cuanto manifiesto he manifestado y manifestaré, [porque] veo mucho, inquiero más y los instrumentos de sacerdotes, escribanos y otras personas me deben hacer fuerza, que son cristianos y yo deseo tanto el servicio de ambas Majestades que me obliga repetir lo que siento».

El celo no le faltaba. Don Pedro había sido corregidor de Logroño poco tiempo antes, así que, nos dice, conocía la población de la ciudad. No obstante, se ocupó de realizar nuevo padrón, ya que

"para tratar del encabezamiento de esta ciudad me ha parecido muy preciso y necesario hacer un Reglamento especial de la Vecindad de que se compone con las diferencias de estados y tratos que conviene para quedar enterado de su jugo y caudal, que aunque yo había sido su corregidor sabíalo por mayor, pero no tan por menor como ahora se requiere, pues lo voy formando casa por casa, y echo esto se pasará a conferenciar sobre el ajuste del nuevo encabezamiento» ${ }^{13}$.

Don Tomás de Oña, Superintendente de Ciudad Real, Almagro y Villanueva de los Infantes, no fue menos celoso.

\footnotetext{
${ }^{12}$ AGS, CJH, leg. 1459.

${ }^{13}$ AGS, CJH, legs 1444, 1459 y 1470.
} 
«Para estos encabezamientos y transacciones - decía- ha precedido la diligencia de mi personal reconocimiento de los pueblos más principales y los de inferior consideración, como son Almagro, Manzanares, Valdepeñas, Daimiel, El Moral, Torralba, Carrión, Bolaños, Miguelturra, Malagón y Ciudad Real, a donde he pasado con mi audiencia y enterándome de sus frutos, tratos y labores, vecindad, sustancia y contratiempos públicos y particulares, interviniendo vista de ojos, reconocimiento y especulación de papeles y particular escrutinio y seguros informes de la constitución y estado de cada uno. $\mathrm{Y}$ en los de menor consecuencia, los testimonios, instrumentos y seguras noticias que han precedido, así de los ministros más prácticos y de los de mi audiencia, como de otras personas de inteligencia en estos manejos. Y en fe de este conocimiento se ha contratado [el encabezamiento] midiendo a cada pueblo para el beneficio con las circunstancias de su necesidad, procurando distribuir la gracia y benignidad de V.Mgd. a proporción de las necesidades, pesándolas para el alivio por sublevar las mayores donde la carga de las contribuciones descomparaba el hombro de las fuerzas y donde el estrago de los tiempos se había señalado con más gravedad» ${ }^{14}$.

Al parecer, el Superintendente de Jaén no fue el único en confeccionar nuevos padrones. También debió hacerse lo mismo en Extremadura, porque Don Luis Pacheco anunciaba al Consejo desde Plasencia en carta del 29 de abril de 1684 que a la primera ocasión enviaría las escrituras de encabezamientos, los testimonios de arbitrios y los padrones de vecindad, «que por ser cosa de mucho bulto no van por el correo» ${ }^{15}$.

Las estimaciones por redondeo tan frecuentes en la época podían ser o no acertadas según la perspicacia del observador. En cambio, el procedimiento seguido en 1683 parece en principio riguroso y, a la vista de los testimonios anteriores, resulta razonable concluir que los ministros reales se emplearon a conciencia con el fin de disponer de datos ciertos y fidedignos. Las relaciones de vecindad fueron elaboradas mediante examen directo «calle hita» cuando fue posible, como en las mayores localidades, $\mathrm{y}$, cuando no, por medio de informes y documentos de la administración local, como libros de repartimientos, vecindarios y padrones que las autoridades municipales mandaban hacer todos los años. Estos recuentos efectuados con fines estrictamente locales también pueden ser considerados fidedignos, ya que a la vista de todos los vecinos difícilmente podía alguno ser eximido del pago de las cargas comunes sin perjudicar abiertamente a los demás. Pues

\footnotetext{
${ }^{14}$ AGS, CJH, leg. 1469.

${ }^{15}$ AGS, CJH, leg. 1478. Al menos llegó el de la ciudad de Plasencia, donde constan los vecinos calle hita con expresión del oficio de cada uno, incluidos laicos y clero secular: Ibid., leg. 1445 .
} 
bien, al actuar así, recurriendo a los testimonios de los documentos municipales, los superintendentes siguieron una larga tradición administrativa que debían conocer bien por sus años de experiencia burocrática ${ }^{16}$. No podía ser de otro modo a la vista de la estrecha relación que había entre las haciendas real y municipal en la recaudación de tributos. Y, lo que es más importante, tampoco tenía por qué resentirse la veracidad de sus informes. En definitiva, si hubiera que juzgar los resultados de la operación por el procedimiento aplicado, la sentencia sería, sin duda, positiva. No obstante lo dicho, la precaución aconseja comprobar en la medida de lo posible hasta qué punto los datos que ofrece son verosímiles o no.

\section{A VUELTAS CON EL VIEJO PROBLEMA DEL COEFICIENTE DE HABITAN- TES POR VECINO}

Al igual que los demás recuentos fiscales el de 1683 indica el número de vecinos, no el de habitantes. Ningún superintendente llevó el rigor por conocer el estado cierto de la población hasta el punto de contar el número de habitantes, todo lo más a distinguir oficios o valorar cabañas, haciendas y producciones. Pero como lo que realmente interesa en el estudio de la población es el número de individuos, henos aquí de nuevo ante el eterno problema del coeficiente de transformación de vecinos en habitantes.

Cabe preguntarse si aún es posible decir algo nuevo al respecto. Lo único cierto es que se trata de una cuestión simple pero espinosa. En principio, el concepto de vecino es similar pero no idéntico al de familia y casa abierta. Unos y otros han servido indistintamente para elaborar relaciones de vecindad, y todos ellos han resultado ser muy variables en tiempo, lugar y contexto social, así como en virtud de las contribuciones fiscales para las que han sido utilizados.

Las situaciones podían ser muy complejas. Unas veces las unidades familiares se descomponían en varios vecinos cada una y otras al revés, de modo que el número de vecinos resultaba ser mayor o menor que el de casas y familias. De hecho, una misma localidad podía disponer de varias relaciones de vecindad para un mismo año, unas referentes a vecinos de contribución y otras a vecinos de jurisdicción ${ }^{17}$, incluso según qué tipo de contribución -moneda forera, alcabalas o servicios- el número de vecinos podía ser diferente. Los ejemplos de Barcial de la Loma (Valladolid) y Las Navas del Marqués (Ávila) son elocuentes al respecto:

${ }^{16}$ Martín Galán (1985, p. 629) menciona un interesante testimonio respecto al vecindario de 1528. Vid. asimismo los comentarios de Rueda Fernández (1989, pp. 92-103) a propósito de Zamora. Domínguez Ortiz (1992, p. 58) califica los informes realizados a instancia del Consejo de Hacienda para la venta de lugares o la rebaja de tributos como «dignos de todo crédito».

${ }^{17}$ Martín Galán (1985, p. 607). Los padrones de la Provincia de Álava proporcionan la información necesaria para distinguir familias u hogares y vecinos, vid. Bilbao (1999, pp. 278-289). 


\section{CUADRO 1}

\section{EVOLUCIÓN DEL NÚMERO DE VECINOS DE DOS LOCALIDADES DE CASTILLA}

\begin{tabular}{|c|c|c|c|c|}
\hline & \multicolumn{2}{|c|}{ Barcial de la Loma } & \multicolumn{2}{c|}{ Las Navas del Marqués } \\
\cline { 2 - 5 } & Moneda Forera & Servicio & Moneda Forera & Servicio \\
\hline 1662 & 268 & & & \\
\hline 1665 & & 258 & & \\
\hline 1680 & 121 & 118 & & \\
\hline 1681 & & & 740 & 706 \\
\hline 1682 & & & 744 & 693 \\
\hline 1683 & & & 744 & 686 \\
\hline 1684 & & 89 & 719 & 636 \\
\hline 1685 & & & 296 & 306 \\
\hline
\end{tabular}

Fuente: AGS, CJH, legs. 1487 y 1966.

Además de la tendencia que señalan estos vecindarios, llama la atención la distinta relación de vecinos en los mismos años según qué vecindarios. Barcial de la Loma tenía 121 o 118 vecinos en 1680 según el padrón de moneda forera y el repartimiento de servicio, respectivamente, lo que podría ser explicado por la inclusión o no de los hidalgos, aun cuando, en el caso de que los hubiera, el servicio se repartiera a todos los vecinos por igual. Ahora bien, en Las Navas del Marqués los repartimientos del servicio real, del que los hidalgos estaban teóricamente exentos, recogían sistemática y sorprendentemente más vecinos que los de la alcabala, un impuesto universal al que todos estaban obligados, menos en el año de 1685 en que el exceso de vecinos en el último repartimiento de alcabalas respecto al del servicio real del mismo año se debe, dice el documento, a que en éste no se incluyeron a los menores. Así pues, los criterios aplicados por las autoridades locales podían variar considerablemente de un padrón a otro incluso en el mismo año. De este hecho se sigue obviamente que según cual sea la naturaleza de los vecindarios elegidos el coeficiente puede variar en una proporción no desdeñable, desde el 2,5 por cien en la primera de las dos localidades citadas el año 1680 hasta el 13,05 por cien en la segunda en el año de 1684. Es decir, lo que va del coeficiente 3,75 al 4 y de éste al 4,5.

La cuestión no termina aquí, de hecho se complica porque, además, el coeficiente varía a lo largo del tiempo en virtud de dos grandes fuerzas, unas demográficas y otras económicas. La baja mortalidad y la elevada fecundidad que parecen caracterizar las épocas de expansión permitirían la formación de familias numerosas y la supervivencia de más hijos a la edad adulta, pero también la temprana 
fragmentación de los hogares por medio de una nupcialidad más intensa como resultado de las crecientes oportunidades de empleo que demandaba una economía en crecimiento. Por el contrario, la elevada mortalidad y la baja fecundidad que parecen predominar en las épocas de declive, como el siglo XVII, disminuirían el tamaño medio de las familias. Ahora bien, las crisis prolongadas forzaban el abandono de las familias sin propiedades para acudir en busca de ayuda a los centros de caridad de las poblaciones urbanas, quedándose en los pueblos, cabe suponer, las familias más acomodadas y, en consecuencia, las más numerosas. En determinadas coyunturas económicas de escasa circulación monetaria, la deflación y la consiguiente tendencia al autoconsumo inducirían una baja demanda de mano de obra asalariada, que, a su vez, forzaría la retención de los hijos y de los criados domésticos, de modo que la familia aumentaría de tamaño.

Así pues, las fuerzas dominantes parecen contrapuestas. ¿Qué dicen las fuentes al respecto? Una prueba de la dificultad de elegir un coeficiente adecuado procede del Catastro de Ensenada. Esta operación recoge el número de vecinos de cada localidad en la 21 ${ }^{\mathrm{a}}$ pregunta del Interrogatorio General y el número de familias u hogares en las Respuestas Particulares o Memoriales, información esta última que sirvió para elaborar los Libros de lo Personal de seglares y eclesiásticos de cada población. El número de vecinos que resulta de una y otra documentación no suele coincidir, siendo habitualmente más elevado en este último caso que en el primero. La causa no es la ocultación deliberada, sino la aplicación de criterios diferentes. De entrada, los vecinos en sentido estricto eran los titulares de ciertos derechos y obligaciones comunes derivadas de la propiedad, la residencia y el arraigo en la localidad que les diferenciaba de los meros residentes o domiciliarios, diferencia sin duda importante en cuanto que determinaba el acceso a los recursos comunales y el reparto de las cargas fiscales ${ }^{18}$. Ahora bien, cuando las Respuestas Generales precisan qué entendieron los peritos por vecino suelen decir que las viudas se contaron por mitad, aunque no siempre, mientras que los habitantes y residentes a menudo no fueron siquiera considerados como vecinos, mientras que los clérigos unas veces fueron incluidos y otras no.

Por su parte, los Libros de lo Personal se aproximan a los padrones sin llegar a ser estrictamente idénticos, si bien las informaciones que ofrecen los declarantes permiten identificar a los grupos domésticos u hogares. En cuanto al llamado Censo de Ensenada conviene recordar que es un resumen hecho a posteriori en el que se estableció el número de vecinos y el de habitantes a partir, según indica la misma fuente, de las Respuestas Particulares y de las preguntas $28^{\mathrm{a}}$ y $31^{\mathrm{a}}$ a $38^{\mathrm{a}}$ del Interrogatorio General y no del vecindario que se cita en las Respuestas Generales. En consecuencia, disponemos para la misma fecha de dos, si no de tres coeficientes distintos, que, además, varían considerablemente de una a otra provincia.

${ }^{18}$ Mateos (1966, p. 14). Vid. un estudio de caso en Pérez Álvarez (1996, pp. 56-59). 


\section{CUADRO 2}

\section{VECINOS, FAMILIAS Y HABITANTES SECULARES SEGÚN EL CATASTRO DE ENSENADA (1752)}

\begin{tabular}{|c|c|c|c|c|c|c|}
\hline & \multicolumn{2}{|c|}{ Vecinos } & \multirow{2}{*}{\begin{tabular}{|l|} 
Individuos \\
Seculares
\end{tabular}} & \multicolumn{2}{|c|}{ Coeficiente } & \multirow{2}{*}{$\begin{array}{c}\text { Población } \\
\text { Total }\end{array}$} \\
\hline & (1) & (2) & & (1) & (2) & \\
\hline \multicolumn{7}{|c|}{ ANDALUCÍA } \\
\hline Córdoba & & 56.529 & 217.270 & & 3,84 & 222.393 \\
\hline Granada & & 133.850 & 536.153 & & 4,01 & 545.285 \\
\hline Jaén & 40.474 & & 166.733 & 4,12 & & 172.236 \\
\hline Sevilla & & 155.595 & 676.297 & & 4,35 & 694.771 \\
\hline \multicolumn{7}{|c|}{ CASTILLA LA VIEJA Y LEÓN } \\
\hline Ávila & 23.925 & 26.489 & 96.145 & 4,02 & 3,63 & 98.873 \\
\hline Burgos & 96.304 & 102.104 & 411.613 & 4,27 & 4,03 & 420.422 \\
\hline León & & 142.680 & 556.567 & & 3,90 & 563.698 \\
\hline Palencia & & 25.552 & 101.304 & & 3,97 & 103.846 \\
\hline Salamanca & 43.324 & 43.511 & 164.888 & 3,81 & 3,79 & 170.424 \\
\hline Segovia & 34.854 & 36.947 & 140.079 & 4,02 & 3,79 & 143.400 \\
\hline Soria & 38.832 & 44.765 & 157.161 & 4,05 & 3,51 & 159.534 \\
\hline Toro & & 22.590 & 77.131 & & 3,41 & 79.212 \\
\hline Valladolid & & 46.717 & 179.899 & & 3,85 & 186.985 \\
\hline Zamora & & 15.513 & 60.786 & & 3,92 & 62.304 \\
\hline \multicolumn{7}{|c|}{ CASTILLA LA NUEVA } \\
\hline Cuenca & 61.626 & 63.539 & 234.617 & 3,81 & 3,69 & 237.487 \\
\hline Guadalajara & 25.333 & 25.287 & 99.979 & 3,95 & 3,95 & 102.070 \\
\hline La Mancha & 43.298 & 51.117 & 168.949 & 3,90 & 3,31 & 183.574 \\
\hline \multicolumn{7}{|l|}{ Madrid } \\
\hline Provincia & 15.155 & 14.851 & 54.979 & 3,63 & 3,70 & 56.123 \\
\hline Villa & & 30.626 & & & & 148.000 \\
\hline Toledo & 78.656 & 81.097 & 304.718 & 3,87 & 3,76 & 313.718 \\
\hline \multicolumn{7}{|c|}{ EXTREMADURA } \\
\hline & 100.768 & 123.627 & 361.887 & 3,59 & 2,93 & 373.022 \\
\hline GALICIA & & 336.057 & 1.286 .138 & & 3,83 & 1.299 .312 \\
\hline MURCIA & & 59.135 & 266.818 & & 4,51 & 272.057 \\
\hline MEDIA & & & & 3,97 & 3,76 & \\
\hline
\end{tabular}

Fuentes: (1) Vecinos según la $21^{\text {a }}$ respuesta al Interrogatorio General, Mateos (1966, p. 14), Calonge Matellanes et al. (1967, p. 18), Marcos González (1971, p. 16), y BRAH, 9/6287 a 9/6330 y 9/6338, 9/6340, 9/6342 a 9/6349, 9/6358 a 9/6359. (2) Vecinos según el llamado Censo de Ensenada. Esta información y los individuos en Censo (1981), y Grupo ’75 (1977, pp. 58-59), excepto la Provincia de León, en BRAH, sig. 9/ 5506, y la Villa de Madrid, en Carbajo Isla (1987, p. 225). 
Descartados los coeficientes elevados de 4,5 y superiores, últimamente se tiende a situarlo por debajo de 4 siguiendo la relación entre habitantes y familias que apunta el Censo de Ensenada ${ }^{19}$. Los datos de la Cuadro 2 son elocuentes al respecto. Allí donde hemos podido completar la encuesta se observan diferencias no desdeñables entre uno y otro coeficiente. En conjunto, el coeficiente medio de la Corona de Castilla se situaba en 3,76 habitantes por vecino según el Censo de Ensenada, excluidas las provincias de Jaén, León y Murcia y la Corte de Madrid, cuyos vecindarios no aparecen en el citado censo. Por el contrario, a partir del número de vecinos de la respuesta $21^{\mathrm{a}}$ al Interrogatorio General y el número de habitantes del mismo Censo se obtiene un coeficiente algo mayor: 3,9720 . La diferencia es poca -apenas el 6 por cien- pero no despreciable. Ahora bien, ¿cuál es conveniente aplicar en fechas anteriores? Ciertamente la variedad de situaciones es tal que no siempre resulta aconsejable aplicar un coeficiente dado a un vecindario anterior sin conocer, y esto es lo importante, el criterio de vecino que las autoridades aplicaron en cada caso, lo que no siempre es posible saber. Si utilizaron un criterio como el que aparece en las Respuestas Generales, el coeficiente deberá ser mayor que si utilizaron un criterio como el del Censo de Ensenada.

El Vecindario de la sal de 1631 ofrece asimismo el número de habitantes de numerosas localidades en lo que constituye la mayor muestra al respecto de la Corona de Castilla durante la época de los Austria. La media -3,54- es un poco más baja que la del Catastro, si bien resulta de la aplicación en unos casos de unos coeficientes redondeados -3 o $4-$ y en otros de observaciones escrupulosas. En este caso, por ejemplo en Palencia, la media alcanza 3,93 personas por vecino ${ }^{21}$. Por otra parte, en Álava y Cantabria se ha podido observar durante el siglo XVII y en coyunturas demográficas diferentes, de estancamiento en una y de expansión en otra, la misma tendencia al engrosamiento de la familiaa ${ }^{22}$. Ya vimos que familia y vecino no son idénticos, aunque sí tan parecidos que su evolución ha seguido generalmente la misma trayectoria.

Por lo que respecta a la época que nos ocupa, los ejemplos disponibles no son muchos ni, por tanto, concluyentes, pero son coherentes con los efectos que cabría esperar de la profunda deflación monetaria que vivieron los castellanos justamente de 1680 a 1686 y, sobre todo, con los límites superiores que señalan las fuentes ya citadas de 1631 y 1752 . Tal y como se puede observar en el Cuadro 3, la mayoría de los datos procedentes de padrones, vecindarios, libros de matrícula parroquiales y

\footnotetext{
${ }^{19}$ García Sanz (1977, p. 42), Martín Galán (1985, p. 625), Lanza García (1991, p. 72), Fernández Vargas (1996, p. 13), Blanco Carrasco (1999, p. 70), además de otros estudios.

${ }^{20}$ El vecindario del obispado de Sigüenza de 1747-48 ofrece un coeficiente próximo a 4,5 porque los párrocos probablemente computaron las viudas por medios vecinos y, quizás, excluyeron a los menores. Pérez Moreda (1980, p. 135), y Martín Galán (1985, p. 631).

${ }^{21}$ Piquero, Ojeda y Fernández de Pinedo (1991, pp. 83-84).

22 Bilbao (1999, p. 285), y Lanza García (1991, p. 73).
} 
nóminas de eclesiásticos sitúan el coeficiente muy cerca de 4 y en varios lugares por encima de 5 personas por vecino. No obstante, los casos locales siempre presentan alguna particularidad que requiere comentarios específicos.

\section{CUADRO 3}

VECINOSYHABITANTES ENALGUNAS LOCALIDADESCASTELLANASC. 1683

\begin{tabular}{|l|c|l|r|r|r|r|}
\hline Localidad & Año & Documento & (1) & (2) & (3) & (4) \\
\hline Campuzano (Torrelavega) & 1683 & Matrícula & 187 & 234 & 59 & 3,97 \\
\hline Cartagena & 1683 & Padrón & & & & 4,13 \\
\hline Cuenca & & & & & & \\
\hline Ciudad de Cuenca (seglares) & 1693 & Padrón & & 5.641 & 1.464 & 3,93 \\
\hline Clero secular de las ciudades & 1686 & Nómina & & 993 & 165 & 6,02 \\
\hline Clero secular del obispado & 1686 & Nómina & & 3.823 & 1.354 & 2,82 \\
\hline Conventos del obispado & 1686 & Nómina & & 1.392 & 46 & 30,26 \\
\hline Jaén & 1690 & Matrícula & & 2.724 & 712 & 3,83 \\
\hline Mogro (Torrelavega) & 1671 & Matrícula & 275 & 344 & 86 & 4,00 \\
\hline $\begin{array}{l}\text { Moral, El } \\
\text { (Campo de Calatrava) }\end{array}$ & 1685 & $\begin{array}{l}\text { Repartimiento } \\
\text { y Matrícula }\end{array}$ & 1.300 & 1.625 & 328 & 4,95 \\
\hline Murcia & 1683 & Matrícula & 2.100 & 2.770 & 577 & 4,80 \\
\hline Orgaz (Toledo) & 1684 & $\begin{array}{l}\text { Repartimiento } \\
\text { y Matrícula }\end{array}$ & & 2.600 & 473 & 5,50 \\
\hline Rute (Córdoba) & 1684 & Matrícula & 2.924 & 3.535 & 873 & 4,05 \\
\hline Zamora & $1683-5$ & $\begin{array}{l}\text { Padrón y } \\
\text { Relación de } \\
\text { Pobres }\end{array}$ & & & & \\
& & & 5.678 & 1.481 & 3,83 \\
\hline
\end{tabular}

Fuente: Campuzano y Mogro en Lanza García (1991, p. 73), Cartagena en Torres Sánchez (1998, p. 104), Ciudad de Cuenca en Reher (1990, p. 20), clero de Cuenca en AGS, CJH, leg. 1508, Jaén en Coronas Tejada (s.f., p. 13), Moral y Orgaz en AGS, CJH, legs. 1492 y 1511, Murcia en Chacón Jiménez (1986, pp. 39 y 111), Rute en García Jiménez (1987, pp. 355357), y Zamora en Rueda Fernández (1989, pp. 99 y 274). Los datos procedentes de las matrículas parroquiales se refieren a personas de comunión, a las que hemos añadido la población parvularia, que suponemos equivalente a la quinta parte de la población, salvo en Murcia y Rute, en que hemos respetado las proporciones que ofrecen los autores.

Notas: (1) Personas de Comunión. (2) Población total. (3) Vecinos o Familias. (4) Coeficiente.

Para empezar, los vecinos así considerados por los curas no tenían por qué coincidir en número con los registrados en los libros de repartimientos de contribuciones ni en los padrones de vecindad. En todo caso, no deja de ser llamativo el hecho de que los coeficientes que se deducen de los libros de matrícula de Campuzano, Mogro y Rute sean iguales en números redondos a cuatro personas por hogar. Además, estos son, como en seguida veremos, los datos más fiables que manejamos. 
Los datos de las localidades manchegas de El Moral de Calatrava y Orgaz proceden de las certificaciones de los respectivos curas y escribanos locales, que ofrecen, a instancias de los administradores de rentas, el número de personas de comunión y el de vecinos de cada localidad. Los 592 vecinos y las 2.100 personas de comunión que había en El Moral en 1679 quedaron reducidos en 1685 a 328 y 1.300 respectivamente, comprendidos 19 eclesiásticos. Por tanto, si los párvulos representan la quinta parte de la población, el coeficiente habría aumentado de 4,43 a 4,95. En Orgaz las 2.600 «personas de matrícula» de abril de 1683 se correspondían con los 473 vecinos registrados en un repartimiento de servicio del 14 de diciembre de ese año, y las 2.100 personas de la Pascua de 1684 con los 398 vecinos de otro repartimiento de 28 de abril del mismo año, de cuyas cifras se deducen sendos coeficientes de 5,5 y 5,27 habitantes por vecino. Ambos coeficientes son muy altos, aun habiendo incluido a los párvulos, pero, si nos guiamos por el ejemplo anteriormente citado de Las Navas del Marqués es posible que los empadronadores hubieran excluido de las listas a los menores a causa de la crisis de 1684 .

La población eclesiástica de Cuenca presenta unos cocientes que por obvias razones tampoco son extrapolables a los demás estamentos, aunque sí pueden ser útiles a efectos comparativos. Por una parte, los hogares del clero secular del obispado, el rural, tenían 2,82 personas por término medio, mientras que las del clero secular de las ciudades de Cuenca, Huete y San Clemente tenían nada menos que 6,02. Por tanto, si se pondera esta media con la de la población secular de la ciudad de Cuenca en 1693 entonces el coeficiente medio se sitúa en 4,07 personas por vecino.

Ciertamente, en las ciudades sí que parece haber habido coeficientes más elevados que en el campo. Tal y como indica Guillermo Herrero Martínez de Azcoitia en el caso de Palencia, ciudad en la que aplica un coeficiente 5, había más criados, oficiales y otros dependientes entre las familias acomodadas, clérigos y artesanos urbanos que entre los labradores y jornaleros rurales, así como numerosos habitantes y transeúntes que no solían inscribirse en los padrones por no ser considerados vecinos. En Medina del Campo debía llegar a 4,5 como máximo en el siglo XVII. El de Zamora por esas fechas también debía de ser elevado si se atiende a la naturaleza de los documentos de donde procede la información que aparece en el Cuadro 3: el coeficiente 3,83 que resulta de comparar el vecindario municipal de 1683 y la nómina de personas pobres que necesitaron asistencia en el año de 1685 es obviamente inferior a la realidad, ya que el vecindario seguramente debió de disminuir posteriormente a causa de la crisis de 1684 y no toda la población urbana era pobre ni necesitaba acudir a la caridad pública²3.

${ }^{23}$ Herrero Martínez de Azcoitia (1961, p. 16). Marcos Martín (1978, p. 62) y Rueda Fernández (1989, pp. 99 y 274) se inclinan por el coeficiente 4,5 para Medina del Campo y Zamora, respectivamente, aduciendo, además de los documentos, unas razones muy parecidas a las que aquí se exponen, a saber, que el concepto de vecino no es el mismo en todos los recuentos de población. Rodríguez Alemán (2003, p. 66) también utiliza este coeficiente a la vista de los padrones eclesiásticos de la ciudad de Málaga. 
Otra razón adicional a favor de un coeficiente próximo a 4 personas por hogar y no otro inferior, es que en muchos casos como Palencia consta expresamente la referencia sistemática a los hidalgos, menores, pobres, jornaleros, viudas y eclesiásticos, al menos los seculares, por lo que cabe decir que, al respecto, el vecindario de 1683 es completo. Las viudas fueron consideradas como medios vecinos en Burgos y en numerosas localidades donde así se dice expresamente, pero en otras fueron sencillamente sumadas a los demás y en la mayoría ni siquiera se menciona el criterio que siguieron al respecto. Si tenemos en cuenta que los superintendentes, siguiendo la tradición administrativa castellana, recurrieron a las autoridades locales para recabar las relaciones de vecindad y efectuar los padrones pertinentes parece razonable pensar que, a la vista de los datos anteriores y de las características del vecindario será conveniente aplicar un coeficiente próximo o igual a 4 habitantes por vecino, al menos en grandes conjuntos y como término general, ya que en algunos casos urbanos la documentación indica unos coeficientes específicos algo más elevados. Esta opción se refuerza con el ejemplo del Catastro de Ensenada, cuyo vecindario estricto procedente del Interrogatorio General ofrece un coeficiente medio de 3,97 en el conjunto de la Corona de Castilla, una media casi idéntica a la que se obtiene de los datos más fiables del Vecindario de la Sal de 1631. No obstante lo dicho, la solución al dilema depende en parte del resultado del test de natalidad, que ha de permitir comprobar el grado de verosimilitud del vecindario de 1683.

\section{LA VEROSIMILITUD DE LOS DATOS DEL VECINDARIO DE 1683}

Una de las características del régimen demográfico antiguo era que la conducta vital de la población tendía a mantenerse estable a medio plazo. Los cambios en la fecundidad y la nupcialidad no eran desconocidos, pero tendían a ser breves, violentos y reversibles en el curso de las crisis demográficas y más bien graduales en la larga duración. En este caso, los bautismos pueden ser considerados como un indicador bastante aproximado del tamaño y de los movimientos de la población ${ }^{24}$. A partir de estos supuestos podría deducirse fácilmente el número aproximado de habitantes conociendo sólo el número de bautismos y la tasa de natalidad, si no fuera porque esta metodología plantea algunos inconvenientes. Primero, los bautismos reflejan en puridad el tamaño actual de las cohortes infantiles, antes que el de la población total, razón por la cual son muy sensibles a las migraciones. En segundo lugar, la tasa de natalidad podía situarse en una horquilla comprendida entre el 35 por mil y el 45 por mil según el régimen demográfico fuera de menor o mayor presión, respectivamente ${ }^{25}$. Ahora bien, en determinadas

\footnotetext{
${ }^{24}$ Reher (1990, p. 25).

${ }^{25}$ Pérez Moreda y Reher (1986, pp. 467-496).
} 
situaciones de crisis aguda o de fuerte expansión podía descender o sobrepasar dichos umbrales, aunque esto rara vez sucedía durante mucho tiempo seguido.

No obstante haber cierto grado de incertidumbre, la verdad es que el método de las tasas de natalidad proporciona un elemento muy útil para juzgar la bondad de un recuento de población siempre y cuando no se pierdan de vista dos circunstancias muy importantes: la naturaleza del régimen demográfico local y el momento, al alza o la baja, de la población. En condiciones normales, y siempre y cuando los registros parroquiales sean asimismo completos, un cociente muy elevado, superior al umbral antes citado, indica una probable ocultación de efectivos humanos, mientras que una tasa demasiado baja sugiere una posible exageración.

En el Cuadro 4 aparecen los cocientes de natalidad de las localidades en que ha sido posible cruzar los datos del Vecindario de 1683 con los de los registros parroquiales. La incertidumbre acerca del coeficiente aconseja abrir la horquilla multiplicando el número de vecinos por 4 y 4,5. Los bautismos son la media del decenio 1679-88 cuando los autores indican las series anuales y, cuando no es así, la media de la década correspondiente. La elección de un período tan amplio pretende reducir las fluctuaciones demográficas a una media normal que diluye tanto la baja que algunas poblaciones vivieron en los años 1684-85 como el alza que de rebote se produjo en los años inmediatamente siguientes.

Los resultados muestran que estamos ante un vecindario en conjunto verosímil, sobre todo una vez situados estos cocientes en su contexto regional y temporal. Incluso utilizando un coeficiente 4 las tasas resultan inferiores a las que se han encontrado en fechas posteriores en torno al Catastro de Ensenada (1752) y el Censo de Floridablanca (1787), que son fuentes consideradas en general fiables o con escaso margen de ocultación, sobre todo la primera. Las mayores tasas de natalidad se sitúan allí donde las crisis habían sido o menos acusadas o pronto superadas (Andalucía Occidental), y también donde se estaba viviendo ya una incipiente recuperación (León, Logroño, Medina del Campo, Tierra de Campos), en algún caso más que vigorosa (Murcia). Por otra parte, la multiplicación del vecindario por el coeficiente 4 parece reflejar el impacto de la crisis que algunas poblaciones vivieron en diferentes años de esta década, particularmente en Castilla la Nueva en 1684-85, mientras que si aplicamos el coeficiente 4,5 los cocientes resultan un poco bajos.

El comportamiento de las ciudades merece un comentario específico. En general cabe esperar allí cocientes de natalidad más bajos que en el campo, tanto más bajos cuanto más numerosa fuese la población urbana, si bien los determinantes de la nupcialidad y la fecundidad estaban fuertemente condicionados por los patrones característicos de las respectivas regiones. Por eso no deja de llamar la atención la coherencia entre las tasas andaluzas, más bajas que las castellanas y, sobre todo, las murcianas. En Burgos las viudas fueron contadas como medios vecinos y es muy posible que falte el clero regular, así que la tasa de natalidad que se deduce de aplicar el coeficiente 4 parece elevada en un ámbito urbano que, por otra parte, no 


\section{CUADRO 4}

\section{TASAS DE NATALIDAD EN ALGUNAS LOCALIDADES EN TORNO AL VECINDARIO DE 1683}

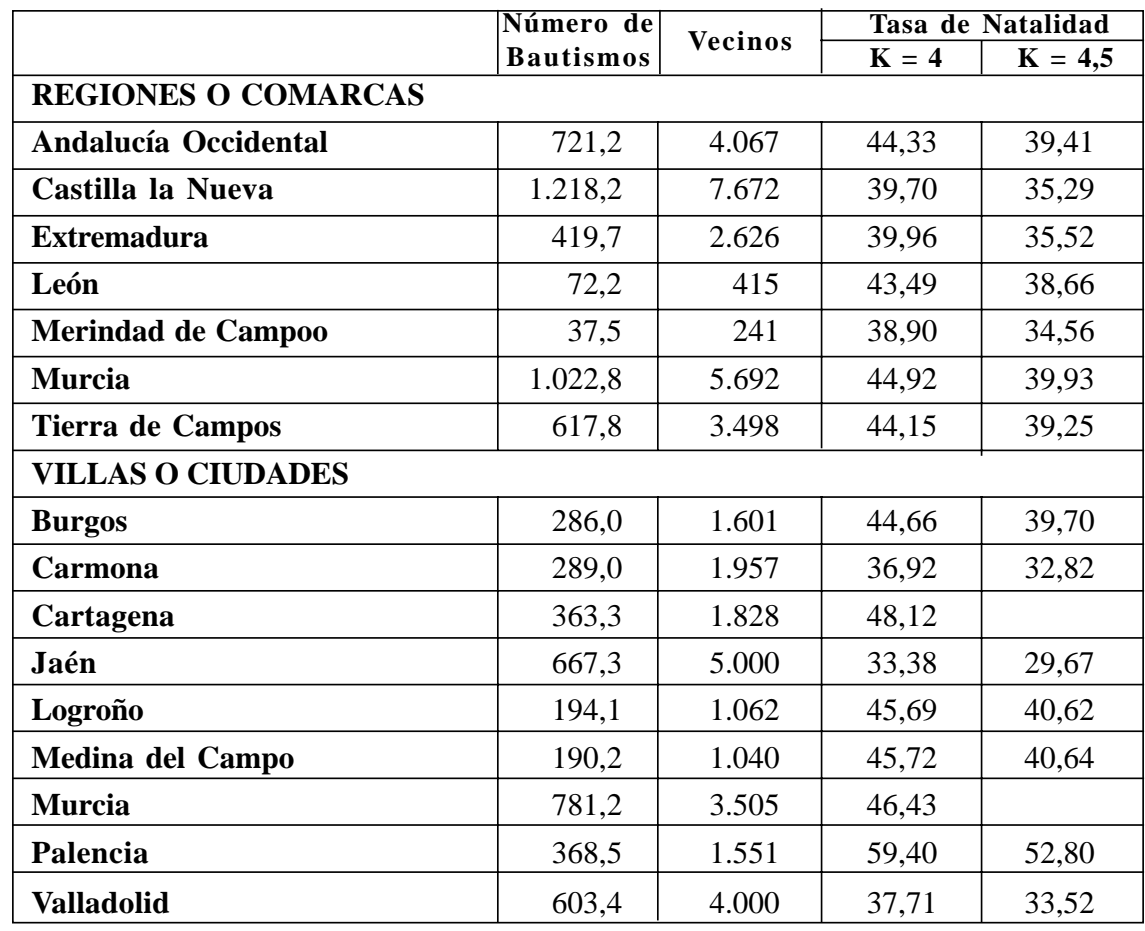

Fuentes: Andalucía: Aznalcázar, Fernán Núñez, Hinojosa del Duque, Hinojos, Montemayor, Rute, Santaella, Umbrete, Valencina de Alcor, y Villanueva de Córdoba, en García Jiménez (1987, p. 316), Ponsot (1986, pp. 137-178), y Valle Buenestado (1978, p. 305). Castilla la Nueva: Almagro, Colmenar Viejo, Miguelturra, El Toboso, Orgaz, Picón, Quintanar, Socuéllamos, Valdepeñas, Villanueva de los Infantes y Yepes, en López-Salazar (1980, Apéndice), y Reher (1991, pp. 21 y 53). Las series de este último aparecen agrupadas en un conjunto del que hemos calculado las correspondientes a la muestra que manejamos considerando que el número de bautismos de cada localidad representa en 1679-88 la misma proporción que la población en el vecindario de 1752, que es la fecha censal completa más próxima al vecindario de 1683. Extremadura: Acebo, Cabeza de Buey, Campanario, Guijo de Galisteo, Monterrubio, Torrejoncillo, Zarza y Zorita, en Rodríguez Grajera (1990) y Llopis Agelán et al. (1990). León: La Bañeza en Rubio Pérez (1987, pp. 77). Merindad de Campoo: Lanza García (1991). Reino de Murcia: Albacete, Alcantarilla, Caravaca, Cehegín, Chinchilla, Cieza y Moratalla, en Chacón Jiménez y González Ortiz (1978-1979), Cremades Griñán (1978-1979), Sancho Alguacil (1987) y Espinosa Núñez (1984, p. 178). Tierra de Campos: Abarca, Castromocho, Frechilla, Guaza, Medina de Rioseco, Villabrágima, Villalón y Villarramiel, en Maza Zorrilla (1979) y Yun (1987, p. 157). Burgos: González Prieto (2003, p. 365). Carmona: Montaño Requena (1987, p. 99). Cartagena: Torres 
Sánchez (1998, p. 104). Jaén: Coronas Tejada (1978, p. 229). Logroño: Lázaro Ruiz (1994, p. 149). Medina del Campo: Marcos Martín (1978, pp. 94-95), corresponden al decenio expansivo de 1670-79 porque en el siguiente faltan los datos de una parroquia importante. Ciudad de Murcia: Chacón Jiménez (1986, pp. 183-219), habiendo añadido los vecinos de Alberca, Campos y Espinardo, pertenecientes al término de la ciudad según González (1829, p. 75), pero de los que no nos consta que tuviesen pila bautismal, como Alcantarilla, incluida en el conjunto del Reino de Murcia. Palencia: Herrero Martínez de Azcoitia (1961, p. 82). Valladolid: Gutiérrez Alonso (1989, p. 30), aunque faltan los registros de la pequeña parroquia de San Martín.

Nota: Los cocientes de natalidad proceden de multiplicar el número de vecinos por un coeficiente $\mathrm{K}=4 \mathrm{y} \mathrm{K}=4,5$. En Murcia y Cartagena hemos aplicado los coeficientes del mismo año 1683 que proponen respectivamente Chacón Jiménez (1986, pp. 39 y 111), y Torres Sánchez (1998, p. 48), a partir de datos originales. Sobre los bautismos ver texto.

mostraba signos entonces de notable crecimiento demográfico ${ }^{26}$. La vecindad de Jaén parece más bien un redondeo al alza, ya que la natalidad que resulta es un poco baja en una población urbana de tales dimensiones, al menos si se compara con Málaga y Granada $^{27}$. La tasa de natalidad de Valladolid está infravalorada en la pequeña proporción que representaba la parroquia de San Martín, cuyos registros han desaparecido, pero el resultado confirma la validez de la cifra de vecinos ${ }^{28}$. En Medina del Campo la natalidad resulta un poco alta porque el número de bautismos en realidad corresponde a la vigorosa década anterior. No obstante, en esta como en las demás ciudades castellanas se vivió una profunda agrarización de sus funciones económicas y probablemente también de su régimen demográfico. De Logroño se puede decir asimismo que había vivido un ciclo fuertemente expansivo, aunque la tasa de natalidad con el coeficiente 4,5 es tan alta como la que se ha podido observar en 1752 y $1787^{29}$. El caso de Palencia suguiere la conveniencia de usar un coeficiente más alto o la falta en el padrón de los moradores no avecindados. Aparte de este caso, Cartagena y Murcia presentan los cocientes más elevados de la muestra: en ambos casos el número de habitantes es el que se deduce, si no de la misma fuente, como en Palencia, de sendos padrón y matrícula parroquial que fueron realizados en la misma fecha, y ambos términos levantinos experimentaban entonces un crecimiento muy vigoroso que casi sin interrupción proseguiría a lo largo del siglo XVIII. Dado el régimen demográfico local caracterizado por la intensa inmigración y la elevada fecundidad no cabe duda que estamos ante un ejemplo, no de ocultación, sino de genuino crecimiento de la población.

\section{LOS DATOS DISPONIBLES: UNA ESTIMACIÓN DE LA POBLACIÓN DE LA CORONA DE CASTILLA EN 1683}

Los superintendentes sometieron a consulta del Consejo de Hacienda los encabezamientos que iban concertando en el curso de la operación con las locali-

\footnotetext{
${ }^{26}$ González Prieto (2003, p. 124).

27 Donde llegaba a 41 por mil y 35 por mil respectivamente, según Rodríguez Alemán (2003, p. 251) y Sánchez-Montes (1989, p. 261).

${ }^{28}$ Aproximadamente la décimo sexta parte. Gutiérrez Alonso (1989, p. 24).

${ }^{29}$ Lázaro Ruiz (1994, p. 39).
} 
dades de las respectivas provincias. Aunque la Real Instrucción no lo menciona, parece que el propósito de las autoridades también era el de elaborar un nuevo vecindario. El contador de Soria Francisco Ortiz de la Torre preguntaba al Consejo en carta de 28 de agosto de 1683 «si en las relaciones [...] de los encabezamientos de esta provincia se podrá omitir la Vecindad y Tratos de cada lugar respecto de que se remitirá testimonio aparte». El contador de la superintendencia de Salamanca certificó un vecindario que lleva fecha de ocho de febrero de 1684 y que sin duda procede de las averiguaciones del año anterior, porque las cifras son reiteradas por el mismo Superintendente en otro documento. Cuando Don Francisco de Guadalfajara remitió al Consejo el 20 de septiembre de 1683 los instrumentos de la operación que había realizado en la provincia de Guadalajara añade que «todo consta por menor de un libro aparte que se ha formado de los lugares, en que se da en cada uno noticia de lo que contiene y sus vecindades y labores y yuntas de mulas y bueyes para la labor del campo» ${ }^{30}$. De las mismas consultas se deduce que había instrucciones para protocolizar las escrituras de encabezamientos, algunas de las cuales se han conservado en el Archivo General de Simancas. Además, la Real Instrucción establecía la obligación de elaborar dos relaciones, una de cientos y alcabalas, en la que debía constar el vecindario, y que no ha podido ser localizada todavía, y otra de servicios de millones. Ambas debían hacerse por duplicado, enviando una al Consejo de Hacienda y dejando otra para la administración de las cabezas de provincia o partido.

Entonces, ¿qué documentación ha sobrevivido? ¿qué alcance tiene verdaderamente el Vecindario de 1683? Algunos de los informes que los Superintendentes enviaron al Consejo se han conservado entre los papeles de las Secretarías de Hacienda y de la Contaduría Mayor de Cuentas. Por desgracia no están todos los que fueron, aunque sí una proporción, como en seguida veremos, bastante notable y que creemos suficiente para abordar el estudio de la población castellana a finales del siglo XVII.

De las veintiuna provincias castellanas de entonces, a la que se sumaría varias décadas después la de La Mancha, disponemos de información total o parcial de todas excepto de tres, que son Galicia, Madrid y Cuenca. Entre las primeras están Ávila, Palencia, Salamanca, Soria y Valladolid en Castilla la Vieja, y Guadalajara en Castilla la Nueva. De los reinos de Córdoba y Murcia sólo faltan la ciudad de Córdoba, Pozoblanco, Fuenteovejuna y Jumilla, ésta porque entonces tributaba en Cuenca y las andaluzas porque no llegaron a concertar los encabezamientos. En las demás provincias, las localidades cuyo vecindario es conocido representan proporciones en general elevadas: el 72,19 por cien en Zamora, el 44,98 en Toro, el 47,13 en Toledo, el 55,12 en La Mancha, y el 37,15 en Extremadura. En

${ }^{30}$ AGS, CJH, leg. 1459 (Soria) y 1461 (Guadalajara), y CMC, 3ª época (Salamanca). 
Andalucía las muestras van, aparte de Córdoba, desde el 34,98 por cien en Granada hasta el 38,23 en Jaén y el 38,59 en Sevilla. Los datos disponibles en León y Burgos son más escasos: el 12,94 por cien y el 19,85 por cien respectivamente. En Segovia sólo hay información de unos pueblos serranos cuya muestra parece muy insuficiente para aventurar un cálculo de la población provincial. Las proporciones anteriormente citadas han sido elaboradas por aproximación tomando como referencia el llamado Vecindario de Ensenada, que es la documentación desagregada a escala local más homogénea, pues el número de habitantes se refiere a las provincias y sólo en Toledo también a pueblos, villas y ciudades. Por tanto, el procedimiento para conocer la amplitud de la muestra ha sido muy sencillo: hallar la proporción que representan respecto a los vecinos de 1752 los de aquellas localidades cuyo Vecindario de 1683 conocemos.

A partir de estos datos creemos que es posible realizar una estimación de la población castellana a mediados del reinado de Carlos II. La reconstrucción de la población de Castilla en 1683 se apoya en el supuesto, bien sencillo y razonable, de que la población de cada provincia evolucionó en el mismo sentido que el de la población de la muestra respectiva. Obviamente, el margen de error dependerá de la amplitud de la muestra, pero la que hay a nuestra disposición es tan amplia como segura a los efectos estadísticos que se persiguen. Ciertamente, lo ideal sería disponer de una información completa, pero cuando no queda más remedio que manejar muestras reducidas, y la que manejamos no es inferior a las que son habituales en la actualidad, se espera que no haya grandes diferencias de comportamiento entre las poblaciones conocidas y las demás. Cuanto mayor sea la muestra menor será la probabilidad de que el resultado sea alterado por el comportamiento de una parte de la población no conocida. Por último, una vez conocido por este procedimiento el número de vecinos de cada provincia, el resultado ha sido multiplicado por el coeficiente 4 para obtener el número de habitantes, siguiendo los argumentos que se expusieron en las páginas anteriores.

Además, allí donde ha sido posible hemos completado las lagunas con los datos procedentes o bien del mismo Consejo de Hacienda o bien de estudios recientes. En el primer caso se trata de las averiguaciones abiertas a instancias del Consejo con el fin de comprobar el estado de las poblaciones que solicitaban remisiones de débitos o rebajas tributarias. En el segundo, se trata de estimaciones a partir de padrones y registros parroquiales. Conviene no perder de vista que se trata de datos cuyo valor ha sido doblemente verificado, en su momento por los ministros de hacienda, dignos de todo crédito según Domínguez Ortiz, y ahora, en los estudios correspondientes, por medio del test de natalidad. Siguiendo esta lógica no podemos aceptar como ciertos cualesquiera testimonios. Así, la villa de Marchena representaba en 1686 que de 4.000 vecinos que decía haber tenido solamente habían quedado 1.194, pero las series de bautismos publicadas 
por P. Ponsot demuestran que nunca pudo alcanzar ni una ni otra población ${ }^{31}$. En cambio, sí son verosímiles los informes elaborados en fechas diferentes por los ministros de hacienda sobre los vecindarios de Almagro, Aranda de Duero o Valdepeñas, por señalar algunos ejemplos ${ }^{32}$. Si las autoridades locales deformaban la realidad en los memoriales que presentaban al Consejo, las averiguaciones «por vista de ojos» recababan informes sin duda objetivos. La diferencia entre estos documentos y los anteriores radica en el origen de las informaciones. En todo caso, sólo es posible admitir las relaciones que se refieren al año 1683 y a los inmediatamente anteriores, ya que la crisis de mortalidad de los años 1684-85 redujo la población en muchas comarcas del interior en una proporción que seguramente no se recuperó hasta la década siguiente ${ }^{33}$.

La población de otras localidades y regiones se conoce razonablemente bien gracias a varios estudios recientes. La población de Galicia es la correspondiente al año 1683 según la tasa de crecimiento entre 1631 y 1708 que propone Eiras Roel una vez corregidas al alza las cifras del vecindario de la sal ${ }^{34}$. La población de la villa de Madrid es la que apunta Carbajo Isla (1987, p. 225) a partir de una relación de personas de confesión del mismo año 1683. La de las provincias de Cuenca, Madrid y Segovia se puede deducir de las respectivas proporciones regionales en el vecindario de 1752. La bondad de este procedimiento puede ser contrastada al menos en el caso segoviano. En efecto, el vecindario de esta provincia en 1683 es el mismo que se deduce multiplicando los 34.854 vecinos de 1752 por el índice de bautismos de 1680-1689 respecto al de 1750-1759 elaborado por García Sanz ${ }^{35}$. No hallamos forma de contrastar el resultado correspondiente a Cuenca y a los pueblos de la provincia de Madrid, pero es razonable pensar que su comportamiento no debió de apartarse sustancialmente de la media de Castilla la Nueva, que es el resultado de un ascenso moderado en Guadalajara y Toledo y un crecimiento bastante vivo en La Mancha. La proximidad geográfica y la similitud de rasgos socioeconómicos hacen pensar en un comportamiento no muy diferente del conjunto de la región. En cuanto al partido de Laredo, su población debió de

${ }^{31}$ AGS, CJH, leg. 1504, y Ponsot (1986, pp. 137-178). Otro ejemplo es el de las Siete Merindades de Castilla la Vieja, cuyo vecindario debe de referirse a los contribuyentes, porque de lo contrario la población habría crecido hasta 1752 a unas tasas increíbles.

${ }^{32}$ Los datos de vecindad en AGS, CJH, legs. 1461 y 1513, y Moral García (1991, pp. 187190), los de bautismos en esta misma obra y López-Salazar (1980, Apéndice).

${ }^{33}$ Algunos testimonios documentales de este declive en Kamen (1981, pp. 92-93). El mejor y más amplio estudio sobre esta crisis de mortalidad sigue siendo el de Pérez Moreda (1980, pp. 304-305).

${ }^{34}$ Eiras Roel (1996, p. 105) propone 735.000 habitantes en 1631 y 1.067 .856 en 1708,de modo que la tasa de crecimiento anual entre ambas fechas eleva la población gallega en 1683 a 950.000 habitantes.

${ }^{35}$ El índice 76 del primer decenio respecto al índice 106 del segundo, ambos con base 100 en 1720-1749 y procedentes de los bautismos de 18 parroquias, multiplicado por el citado vecindario de 1752 da 24.990 vecinos, apenas un 0,16 por cien inferior al que se deduce del procedimiento utilizado en el texto. Vid. García Sanz (1977, p. 53). 


\section{CUADRO 5}

\section{ESTIMACIONES DE LA POBLACIÓN DE ALGUNAS REGIONES Y LOCALIDADES A FINALES DEL SIGLO XVII SEGÚN FUENTES DIVERSAS}

\begin{tabular}{|l|r|r|r|}
\hline & Vecinos & & Habitantes \\
\hline Galicia & & & 950.000 \\
\hline Cádiz & & & 32.500 \\
\hline Sevilla & & & 50.000 \\
\hline Córdoba & 8.000 & & \\
\hline Ciudad de Granada & 8.913 & & \\
\hline Ciudad de Guadix & 1.500 & inc. las cuevas extramuros & \\
\hline Ciudad de Baza & 1.400 & & \\
\hline Vera & 500 & & \\
\hline Purchena & 250 & & \\
\hline Mojácar & 200 & & \\
\hline Ciudad de Almería & 2.000 & inc. huertos y arrabales & \\
\hline Carriles (Baza) & 600 & & \\
\hline Zújar & 300 & & \\
\hline Ciudad de Antequera & 4.400 & & \\
\hline Ciudad de Ronda & 2.800 & & \\
\hline Ciudad de Marbella & 500 a 600 & todos soldados y marineros & \\
\hline Ciudad de Málaga & 4.296 & & \\
\hline Illora & 790 & & $125.000 / 130.000$ \\
\hline Nerja & 230 & & \\
\hline Otura de la Vega & 290 & & \\
\hline Madrid & 96.000 & personas de comunión & \\
\hline
\end{tabular}

Fuente: Córdoba: Fortea Pérez (1978). Galicia: suponiendo la tasa de crecimiento anual del período 1631-1708 que se deduce a partir de las poblaciones de ambas fechas propuestas por Eiras Roel (1996, p. 105). Granada: Sánchez-Montes (1989, p. 261). De Guadix a Marbella, AGS, CJH, leg. 1988. Málaga, Illora y Nerja: Vincent (1981, p. 354). Otura de la Vega: AGS, CJH, leg. 1459. Madrid: Carbajo Isla (1987, p. 225). Cádiz: Molina Martínez (2004, p. 69). Sevilla: Domínguez Ortiz (1981, p. 141).

seguir la misma trayectoria que las series de bautismos, que señalan un índice ligeramente mayor en 1683 que en 1752 . El resultado coincide además con la población de 1708 que ha podido ser reconstruida a partir de las visitas parroquiales del arzobispado de Burgos ${ }^{36}$. Por último, aunque el Vecindario de 1683 no men-

\footnotetext{
${ }^{36}$ La mayor parte del partido coincidía con la actual Cantabria. Algunas jurisdicciones pasaron posteriormente a la actual provincia de Burgos, mientras que la población del partido de Reinosa, ahora en esta comunidad, pertenecía a la provincia de Toro. Vid. Lanza García (1991, pp. 86-91).
} 
ciona la población de las grandes ciudades andaluzas de Córdoba, Granada, Sevilla, Cádiz y Málaga, por suerte varios estudios de gran calidad han aventurado sendas estimaciones en fechas muy próximas ${ }^{37}$. A estos datos se pueden añadir los que se indican en la Visita del Consejo de Castilla de 1693 sobre varias localidades del Reino de Granada y la ciudad de Antequera.

El resultado es el que aparece en el Cuadro 6, a la vista de cuyos datos podemos extraer unas primeras conclusiones obviamente provisionales y que nuevos documentos deberían ayudar a comprobar y, en su caso, rectificar.

En primer lugar, la población de Castilla había alcanzado en 1683 la cifra de 4.786.882 habitantes, sin contar las provincias forales. La región más poblada era Andalucía con 1.117.880 habitantes, que representaban el 23,35 por cien de toda la Corona de Castilla, casi el mismo porcentaje que en 1752. Castilla la Vieja y León, con La Rioja pero sin Asturias ni Cantabria, tenía 1.087.202 habitantes, que hacían el 22,71 por cien del total. El hecho de que las poblaciones de la cornisa cantábrica junto con la de Galicia sumaban el 29,59 por cien no debe sorprender, pues la trayectoria que habían vivido en las décadas inmediatamente anteriores fue totalmente contraria a la del interior. Castilla la Nueva solamente tenía 776.080 habitantes y el 16,21 por cien del total, mientras que los 291.370 habitantes de Extremadura y los 98.150 de Murcia equivalían al 6,09 y al 2,05 por cien de toda la población de toda Castilla.

En segundo lugar, el Vecindario de 1683 ofrece una interesante panorámica de la evolución de la población de Castilla, al tiempo que permite valorar el alcance de la depresión del siglo XVII y situar la recuperación posterior. La población de 1683 era todavía una décima parte menor que un siglo antes y apenas un 3 por 100 mayor que la de 1631 . La caída respecto a 1591 debería ser aún mayor si tenemos en cuenta las dudas que ha despertado el vecindario de esa fecha, hasta el punto de que algunos investigadores han propuesto elevar sus cifras por lo menos en Andalucía y Galicia en un 20 por $100^{38}$. Las ganancias de 1631 a 1683 parecen haber sido muy pequeñas, pero es que tampoco podían ser mucho mayores. En efecto, la temprana y viva recuperación de la costa noratlántica, la más tardía pero aún más vigorosa de Murcia y el eventual aunque modesto crecimiento de la Villa de Madrid contrastan con el virtual estancamiento de Andalucía, ambas Castillas y Extremadura, donde vivía la mayor parte de la población de la Corona

\footnotetext{
${ }^{37}$ Fortea Pérez (1978), Sánchez-Montes (1989), Domínguez Ortiz (1981) y Vincent (1981).

${ }^{38}$ Vid. respectivamente Pérez García (1995, p. 32), y Eiras Roel (1996, p. 26). Asimismo Fortea Pérez (1980, p. 61). Por el contrario, quienes afirman que los datos de este vecindario son exagerados se refieren a ambas Castillas. Vid. Reher (1991, p. 34) y Marcos Martín (1978, p. 67). Domínguez Ortiz (1992, p. XII) creía que los defectos y las exageraciones tal vez se compensaban entre sí. No obstante, la discrepancia puede esconder la aplicación implícita de criterios diferentes de vecindad en la fuente original más que coberturas diferentes, aunque es indudable que al menos en Galicia faltan numerosas localidades.
} 


\section{CUADRO 6}

\section{EL VECINDARIO DE 1683, DATOS ORIGINALES Y RECONSTRUCCIÓN}

\begin{tabular}{|c|c|c|c|c|c|c|c|}
\hline & (A) & (B) & (C) & (D) & $(\mathrm{E})$ & (F) & $(\mathrm{G})$ \\
\hline \multicolumn{8}{|l|}{ Córdoba } \\
\hline Provincia & 32.532 & 47.027 & 48.239 & 97,49 & 33.3701 & 33.480 & \\
\hline Ciudad & - & - & 9.973 & - & 8.000 & 32.000 & \\
\hline Total & - & - & 58.212 & - & 41.370 & 165.480 & \\
\hline \multicolumn{8}{|l|}{ Granada } \\
\hline Provincia & 26.593 & 43.095 & 123.214 & 34,98 & 76.025 & 304.100 & \\
\hline Ciudad & - & - & 13.651 & - & - & 53.000 & \\
\hline Total & - & - & 136.865 & - & - & 357.100 & \\
\hline Jaén & 14.182 & 15.473 & 40.474 & 38,23 & 37.100 & 148.400 & \\
\hline \multicolumn{8}{|l|}{ Sevilla } \\
\hline Provincia & 30.564 & 48.786 & 126.418 & 38,59 & 79.200 & 316.800 & \\
\hline Ciudad de Sevilla & - & - & 19.666 & - & - & 80.000 & \\
\hline Antequera & - & - & 5.639 & - & 4.400 & 17.600 & \\
\hline Cádiz & - & - & 9.842 & - & - & 32.500 & \\
\hline Total & - & - & 161.565 & - & - & 446.900 & \\
\hline ANDALUCÍA & & & & & & 1.117 .880 & 23,35 \\
\hline Cuenca & - & - & 61.627 & 0,00 & 42.547 & \begin{tabular}{|l|}
170.188 \\
\end{tabular} & \\
\hline Guadalajara & 21.466 & 25.287 & 25.287 & 100,00 & 21.466 & 85.864 & \\
\hline La Mancha & 14.851 & 26.942 & 51.117 & 55,12 & 26.943 & 107.772 & \\
\hline \multicolumn{8}{|l|}{ Madrid } \\
\hline Provincia & - & - & 14.851 & 0,00 & 10.254 & 41.016 & \\
\hline Villa & - & - & 30.626 & 0,00 & - & 130.000 & \\
\hline Toledo & 28.423 & 38.218 & 81.097 & 47,13 & 60.310 & 241.240 & \\
\hline CASTILLA LA NUEVA & & & & & & 776.080 & 16,21 \\
\hline Ávila & 18.225 & 26.489 & 26.489 & 100,00 & 18.225 & 72.900 & \\
\hline Burgos (sin Laredo) & 10.101 & 13.608 & 68.546 & 19,85 & 50.900 & 203.600 & \\
\hline León (sin Asturias) & 6.378 & 8.020 & 63.557 & 12,62 & 50.539 & 202.155 & \\
\hline Palencia & 17.336 & 25.552 & 25.552 & 100,00 & 17.336 & 71.691 & \\
\hline Salamanca & 27.284 & 43.511 & 43.511 & 100,00 & 27.284 & 109.136 & \\
\hline Segovia & - & - & 36.947 & 0,00 & 25.029 & 100.116 & \\
\hline Soria & 26.395 & 44.765 & 44.765 & 100,00 & 26.395 & 105.580 & \\
\hline Toro & 5.033 & 10.162 & 22.590 & 44,98 & 11.894 & 47.576 & \\
\hline Valladolid & 33.832 & 58.178 & 58.178 & 100,00 & 33.832 & 135.328 & \\
\hline Zamora & 7.060 & 11.199 & 15.513 & 72,19 & 9.780 & \begin{tabular}{|l|}
39.120 \\
\end{tabular} & \\
\hline CASTILLA Y LEÓN & & & & & & 1.087 .202 & 22,71 \\
\hline EXTREMADURA & 27.061 & 45.933 & 123.627 & 37,15 & 72.843 & 291.370 & $\overline{6,09}$ \\
\hline MURCIA & 23.454 & 58.335 & 59.135 & 98,65 & 23.775 & 98.150 & 2,05 \\
\hline Galicia & -1 & - & - & 0,00 & - & 950.000 & \\
\hline Asturias & 82.000 & 79.123 & 79.123 & 100,00 & 82.000 & 328.000 & \\
\hline Cantabria & - & - & - & 0,00 & - & 138.200 & \\
\hline COSTA NORATLÁNTICA & & & & & & 1.416 .200 & 29,59 \\
\hline CORONA DE CASTILLA & -1 & - & & - & - & 4.786 .882 & 100,00 \\
\hline
\end{tabular}

Fuente: AGS, CJH, legs. 1443-1511, y CMC, $3^{\mathrm{a}}$ época, leg. 3192.

Nota: (A) Vecinos en 1683 (muestra). (B) Vecinos en 1752 de las localidades de la muestra de 1683. (C) Vecinos de cada provincia en 1752. (D) Porcentaje que representan las poblaciones de la muestra de 1683 en 1752 (B/ C) excluidas las capitales citadas. (E) Vecinos de cada provincia en 1683 (A/D*100). (F) Población de 1683 aplicando un coeficiente 4 excepto en las ciudades de Cartagena, Murcia y Palencia, las de Córdoba, Granada, Sevilla, Antequera y Cádiz, la villa de Madrid, el Reino de Galicia y Cantabria, cuyos datos proceden de las obras citadas en el texto principal y en Cuadro 5. (G) Porcentaje de la población regional en 1683. 
de Castilla y cuyo movimiento difícilmente podía ser compensado por el de las tres primeras ${ }^{39}$. El sentido de esta evolución es aún más evidente si se toma la referencia de 1591 y el hundimiento de ambas Castillas entre esa fecha y 1631.

Algunas comarcas de Castilla, Andalucía y Levante iniciaron un movimiento alcista poco después de mediado el siglo XVII, aunque éste parece haber sido un fenómeno efímero, pues poco después se interrumpió, sin que todavía estén claras las causas de este doble movimiento. En algunos casos se trata de vivas recuperaciones de las poblaciones castigadas por la guerra o las crisis agrarias como en Extremadura, de procesos de sustitución como el protagonizado por Cádiz y sus alrededores a costa del eje Sevilla-Sanlúcar de Barrameda, quizás también de reconversiones hacia actividades de exportación inducidas por la proximidad de mercados urbanos y regionales en expansión, como en algunos pueblos de Segovia y de León que estaban vinculados respectivamente con Madrid y la cornisa cantábrica $^{40}$. Que la población había invertido la tendencia al declive que había dominado durante las primeras décadas del siglo parece evidente ${ }^{41}$. Según H. Kamen, se trata de una temprana recuperación que fue arruinada por la deflación de 1680-86. Sin embargo, esta tesis no parece bien fundada, puesto que presenta como pruebas los vecindarios de 1646 y 1694, que son dos fuentes bien conocidas por sus defectos y ocultaciones ${ }^{42}$. Aun en los casos citados anteriormente se trata más bien de fenómenos incompletos y poco duraderos que llaman la atención por el contraste con la sima de los años 1630-1639/1640-1649. Además, las oscilaciones al alza podían haber sido el resultado, bien conocido en las poblaciones de antiguo régimen demográfico, de los efectos provocados por las clases huecas sobre el movimiento cíclico de la población, y no necesariamente de una recuperación genuina y mucho menos de crecimiento, para los que era preciso el concurso de otros factores, desde la estabilización monetaria hasta la expansión de los mercados urbanos y exteriores. Por último, cabe preguntarse si una vez superadas las dificultades de 1680-1686 fue posible acelerar el crecimiento tanto como para alcanzar el punto de partida de 1591 en los tres últimos lustros del final de siglo.

Así pues, el momento preciso en que se alcanzó la recuperación respecto a las cotas de finales del siglo XVI y dio comienzo el crecimiento propiamente dicho no se conoce muy bien. Sabemos que justamente en 1683 el crecimiento se detuvo

\footnotetext{
${ }^{39}$ Así lo ha sugerido recientemente Marcos Martín (2000, pp. 561-562).

${ }^{40}$ Rodríguez Grajera (1990, p. 69), Bustos Rodríguez (1990, p. 27), García Sanz (1977, p. 84), y Rubio Pérez (1987, p. 77).

${ }^{41}$ Aunque el «panorama se caracteriza más por las luces y sombras que por un crecimiento decidido y claro», recuerda Yun (1999, p. 69). Lo único cierto es la diversidad de comportamientos. Vid. Pérez García (1988, p. 213).

42 Kamen (1981, p. 73). También Fernández Vargas (1996) utiliza ambas fuentes, que en los casos de Galicia, Asturias o Cantabria presentan ocultaciones clamorosas.
} 
en la costa cantábrica, tanto en el partido de Laredo como en Asturias, y que en Galicia se moderó paulatinamente el ritmo hasta casi detenerse en los años 1760. También se conoce relativamente bien el comportamiento de la población de Murcia, que mantuvo una intensa y constante expansión desde 1680 aproximadamente hasta mediados del siglo XVIII y, aunque luego se moderó, siguió siendo más rápido que en el resto de Castilla. Por el contrario, una aparente recuperación en Andalucía, Extremadura y ambas Castillas que se supone habría comenzado c. 1660, si no antes, se esfuma y liquida entre 1679 y 1684 no reanudándose por lo menos hasta entrada la década de 1690 y en algunos casos aún más tarde. En definitiva, la recuperación no parece haberse consolidado por completo antes del fin de siglo.

\section{CUADRO 7}

LA EVOLUCIÓN DE LA POBLACIÓN DE CASTILLA, 1591-1787

\begin{tabular}{|c|c|c|c|c|}
\hline & Población & Índices & \multicolumn{2}{|c|}{ Tasa de Crecimiento } \\
\hline 1591 & 5.302 .000 & 100 & & \\
\hline 1631 & 4.600 .000 & 87 & $1591-1631$ & $-0,35$ \\
\hline 1683 & 4.787 .000 & 90 & $1631-1683$ & 0,08 \\
\hline 1752 & 6.609 .000 & 125 & $1683-1752$ & 0,47 \\
\hline 1787 & 7.298 .000 & 138 & $1752-1787$ & 0,28 \\
\hline
\end{tabular}

Fuente: Los datos de 1591 y 1787 en Nadal (1984, pp. 74-75), los de 1631 en Piquero, Ojeda y Fernández de Pinedo (1991, p. 83), los de 1752 en Grupo’75 (1977, p. 59), excepto la Villa de Madrid, que procede de Carbajo Isla (1987, p. 225), y los de 1683 en Cuadro 6.

La tercera conclusión que se extrae de los datos que proporciona el Vecindario de 1683 se deriva de la anterior. Si el comienzo de la recuperación efectiva de la población castellana fue más tardío de lo que se ha dado a entender, entonces el crecimiento de la primera mitad del siglo XVIII debió haber sido un poco más intenso que el del período 1752-1787: de 0,48 por cien anual en 1683-1752 a 0,28 por cien en el siguiente período.

La geografía del crecimiento durante el período 1683-1752 que señalan ambos recuentos apunta el vigor de las regiones levantina y andaluza y el de las comarcas interiores próximas o de tránsito a estas como La Mancha, así como el de algunas provincias especialmente castigadas por la depresión del siglo anterior como Zamora. Las regiones del interior destacan por la moderación, Galicia por la desaceleración del ritmo de crecimiento y la cornisa por el estancamiento.

La trayectoria de los registros parroquiales también coincide grosso modo con esta evolución, hecho que contribuye a reforzar los datos que se deducen del vecindario de 1683. Las muestras regionales que han sido recopiladas hasta la fecha indican efectivamente que las ganancias de población fueron mayores en 
los decenios anteriores a 1752 que entre esta fecha y el censo de 1787 excepto en la cornisa cantábrica y Galicia, las regiones que más habían crecido durante el período 1631-1683 ${ }^{43}$. En Asturias se vivió un retroceso en 1680-90 que fue seguido por un largo estancamiento hasta 1730-40, y muy parecido en cronología, trayectoria e intensidad fue el caso de Cantabria, hasta el punto de que ambas regiones no sólo reanudaron el nuevo ciclo de crecimiento al mismo tiempo, sino que fueron las únicas que aceleraron el crecimiento, aunque bien poco, en la segunda mitad del siglo XVIII ${ }^{44}$. En Galicia el movimiento alcista de los bautismos también se detuvo en las dos décadas de 1680-1699, si bien desde el mismo cambio de siglo el crecimiento volvió a reanudarse, pero a un ritmo decreciente que se detuvo y retrocedió en 1760-69 justo antes de tomar nuevos bríos ${ }^{45}$. En Andalucía la recuperación de los índices de bautismos que se habían alcanzado a finales del siglo XVI se consumó aparentemente en los últimos años del XVII, momento a partir del cual dio paso a un genuino crecimiento que, aun no siendo muy brillante en conjunto, se aceleró en los años 1710-1719/1750-1759 y luego otra vez se moderó ${ }^{46}$. Asimismo, en Extremadura tanto los registros como los censos coinciden en señalar una intensidad sólo ligeramente mayor del crecimiento anterior a 1752 respecto al de $1752-1787^{47}$. El estancamiento de los bautismos en Castilla la Nueva durante la segunda mitad del XVII dio paso en el cambio de siglo a un crecimiento que se prolongó hasta finales del XVIII pero a un ritmo decreciente desde los años de 1760-177048. Otro tanto cabe decir de Castilla la Vieja y León, aunque en este caso la intensidad del crecimiento parece haber sido menor que en las demás regiones de la antigua Corona de Castilla ${ }^{49}$. El caso más llamativo es indudablemente el del Reino de Murcia, cuya población creció entre 1683 y 1752 a un ritmo de 1,49 por cien anual según los datos que aquí presentamos. Aunque mucho mayor que los demás, no es menos creíble si consideramos que esta región ya había recuperado la población de 1591 en torno a 1694 aproximadamente, que, en consecuencia, entre esta fecha y 1752 se multiplicó al 1,53 por cien anual

\footnotetext{
${ }^{43}$ Un estudio pionero a partir de las series de bautismos agregadas por «regiones históricas» en Nadal (1984, p. 78-81). Para el período concreto de 1650-1760, vid. Pérez Moreda (1997), pp. 147-150. También Llopis (2002, p. 124), pero desde 1700 en adelante.

${ }^{44}$ El comportamiento descrito por Anes (1988, p. 24) se observa también en el caso de Luarca y la Tierra de Valdés, según el magnífico estudio de Fernández Ochoa (1995, p. 94 concretamente). Otras áreas cantábricas no incluidas en el vecindario de 1683, como Guipúzcoa, siguieron un evolución similar. Vid. Piquero Zarauz (1991, p. 65). Cantabria en Lanza García (1991, pp. 87-93).

45 Saavedra (1996, p. 113).

${ }^{46}$ Pérez García (1995, pp. 44-45).

47 Llopis et al. (1990, pp. 459-464)

${ }^{48}$ Reher (1991, pp. 23 y 51-57)

${ }^{49}$ Vid. respecto a Castilla la Vieja el estudio de Marcos Martín (1988, p. 260), y sobre las provincias del centro el de Llopis y Pérez Moreda (2003, p. 129).
} 
según G. Lemeunier, y, por último, que las demás regiones levantinas de Valencia y Cataluña crecieron a ritmos igualmente vivísimos a lo largo del siglo XVIII, sobre todo en su primera mitad ${ }^{50}$.

Por desgracia, no siempre hay forma de conocer la tasa de crecimiento de los bautismos entre las fechas censales de 1683 y 1752 para compararla con la de la población. Aunque no tienen por qué ser exactamente iguales, no tanto a causa de las variaciones que puede experimentar la natalidad en el tiempo, como debido a la muy diferente amplitud de las muestras de los bautismos de que se dispone, lo cierto es que de un reciente estudio de Vicente Pérez Moreda (1997) se deduce que las medias decenales de los bautismos aumentaron en el conjunto de las regiones meridionales y del interior a una tasa de 0,45 por cien anual entre $1679-88$ y 1748-57, mientras que el Vecindario de 1683 y el censo de Ensenada de 1752 arrojan por su parte una tasa del 0,49 por cien anual en el mismo conjunto regional.

\section{CUADRO 8}

\section{EL CRECIMIENTO DE LA POBLACIÓN Y DE LOS BAUTISMOS EN ALGUNAS REGIONES}

\begin{tabular}{|l|c|c|c|c|c|}
\hline & \multicolumn{3}{|c|}{ Población } & \multicolumn{2}{c|}{ Bautismos } \\
\hline & $\mathbf{1 6 8 3}$ & $\mathbf{1 7 5 2}$ & Tasa & Período & Tasa \\
\hline Andalucía & 1.117 .880 & 1.634 .685 & $0,55 \%$ & $1680-89 / 1750-59$ & $0,55 \%$ \\
\hline Castilla la Vieja y León & 1.087 .202 & 1.522 .498 & $0,49 \%$ & $1650-54 / 1756-60$ & $0,61 \%$ \\
\hline Castilla la Nueva & 776.080 & 1.040 .972 & $0,43 \%$ & $1678-88 / 1747-58$ & $0,24 \%$ \\
\hline & & & & $1700-04 / 1750-54$ & $0,51 \%$ \\
\hline Extremadura & 291.370 & 373.022 & $0,36 \%$ & $1679-88 / 1748-57$ & $0,55 \%$ \\
\hline España Interior y Meridional & 3.272 .532 & 4.571 .177 & $0,49 \%$ & $1679-88 / 1748-57$ & $0,45 \%$ \\
\hline
\end{tabular}

Fuente: La población en los Cuadros 2 y 6. Los bautismos de Andalucía en Pérez García (1995, p. 42); Castilla la Vieja y León en Pérez Moreda (1997, p. 149), a partir de la media aritmética de ambos conjuntos, el de Castilla y el de León, y considerando, a la vista de los gráficos adjuntos en las página1s 147-148, que el índice de los bautismos de los años de partida seguía siendo el mismo en torno a 1683; Castilla la Nueva en Reher (1991, pp. 53-55), y LópezSalazar (1976, p. 261), respectivamente; Extremadura en Llopis Agelán (1990, pp. 460-462), y los de la España Interior y Meridional en Pérez Moreda (1997, p. 144).

En Andalucía, la tasa de crecimiento que se deduce de los datos censales es idéntica a la que se deriva de la serie de bautismos elaborada por José Manuel Pérez García, que es la mejor y más amplia de cuantas se dispone. En Castilla la Vieja y León, y lo mismo cabe decir de Extremadura, la primera tasa de crecimiento

${ }^{50}$ Lemeunier (1985, pp. 135-136) cifra la población del antiguo Reino de Murcia en el año de 1694 en 112.502 habitantes, que comparados con los 272.057 de 1752 dan la citada tasa de 1,53 por cien anual. Vid. asimismo Pérez Moreda (1997, p. 144). 
es algo menor que la segunda, lo que sugiere que el Vecindario de 1683 no peca por defecto en estas regiones. En Castilla la Nueva se aprecia el fenómeno contrario si utilizamos la serie de bautismos de D.S. Reher, pero esto, lejos de ser una prueba de ocultación del vecindario, puede ser la consecuencia lógica de que en esta muestra de bautismos predominan las localidades rurales de Cuenca, Guadalajara y Madrid, cuyo crecimiento fue muy moderado, mientras que escasean las de La Mancha, las cuales, por el contrario, vivieron un intensa expansión durante todo el siglo XVIII. La serie de bautismos de J. López-Salazar señala efectivamente un crecimiento aún más intenso que el que se deduce de nuestros datos de población, que se encuentran a mitad de camino entre una y otra serie parroquial $^{51}$. En todo caso, la notable coincidencia que se observa entre la tasa de crecimiento de la población y la de los bautismos en el conjunto interior y meridional no hace sino reforzar la verosimilitud de la información que manejamos.

\section{CONCLUSIONES}

Ante la carencia de fuentes fiables se entiende la permanente incógnita sobre el curso de la población castellana en el largo período que va de 1591 a 1752, tanto como el esfuerzo desplegado por los investigadores mediante el uso de fuentes alternativas y la aplicación de ingeniosos métodos estadísticos.

El empeño de Antonio Domínguez Ortiz por reconstruir la trayectoria de la población mediante el estudio de las ventas de bulas no ha tenido continuidad. En un trabajo ya clásico propuso que el saldo demográfico del siglo XVII fue un virtual estancamiento, de lo que se deduce que la recuperación de la población de 1591 -ya en declive c.1600- aún no se había consumado por completo en 1700. Y aunque esta fuente fiscal no está exenta de problemas, pues el consumo de bulas dependía tanto de la devoción o de la capacidad de convicción de los predicadores como del poder adquisitivo de las familias, los datos locales todavía podrían ser, una vez depurados, de gran utilidad ${ }^{52}$.

Una aproximación muy diferente es la que hace ya tiempo propuso M. Livi Bacci (1968) con la aplicación del método de las poblaciones estables a partir del censo de 1768, que poco después F. Bustelo (1972) extendió utilizando también el de 1787. Aunque, por lo que sabemos sobre el comportamiento de la población española, algunas condiciones de las poblaciones estables, como por ejemplo el

${ }^{51}$ La lista de localidades, en Reher (1991), pp. 20-21. Sobre La Mancha, vid. López-Salazar (1976, p. 261). Decimos que la de Pérez García (1995, p. 42) es la mejor porque se trata de una media ponderada de entidades rurales y urbanas, mientras que las otras parecen ser fundamentalmente rurales.

52 Domínguez Ortiz (1992, pp. XIV-XV). También Bustelo (1989, p. 297) cree que la población española en su conjunto creció muy poco o incluso disminuyó entre 1600 y 1700 . 
crecimiento constante, no se cumplían, lo cierto es que la tasa de crecimiento de la población de Castilla que se deduce de los datos de 1683 y 1787 es justamente 0,40 por cien anual, ligeramente inferior a la que el demógrafo italiano propuso para la población española en el período 1768-1797 y que el ya citado F. Bustelo extendió a todo el siglo XVIII. No obstante, la casi coincidencia puede ser una mera casualidad, pues el mayor impulso de las regiones levantinas implica una tasa de crecimiento algo más intensa en el conjunto de España que en Castilla. En fecha más reciente, D.S. Reher (1991) también ha intentado aplicar un método inspirado en la proyección inversa al estudio de la población rural de Castilla la Nueva, que, a pesar de los prometedores resultados, lo cierto es que no sabemos si ha tenido continuación.

Sin embargo, nada puede ser tan útil como la prueba que ofrecen unos documentos fidedignos. Sabemos que en la época de Carlos II el Estado proseguía el despliegue de una burocracia fiscal poco numerosa pero diligente, capaz de obtener informes precisos y veraces para facilitar la acción del poder real. Las relaciones de vecindad enviadas por los superintendentes a raíz de la reforma fiscal de 1683, tan fiables como los registros parroquiales que han servido para comprobar su verosimilitud, permiten cifrar la población de Castilla sin las provincias forales en 4.787.000 habitantes, $y$, a partir de este dato, proponer una trayectoria general y regional más ajustada a la evolución de los bautismos. Esta población era todavía inferior en una décima parte a la de 1591, mientras que las ganancias respecto a 1631 parecen haber sido en conjunto muy pequeñas, ya que el fuerte crecimiento de la cornisa cantábrica y Galicia no pudo compensar el estancamiento de Andalucía, ambas Castillas y Extremadura. Sólo a partir de 1683, no antes, y probablemente algunas décadas después en algunas regiones, cabe situar el momento en el que la población de la Corona de Castilla inició el movimiento de recuperación tras el declive del siglo XVII.

Por todo lo dicho, esperamos que el descubrimiento del Vecindario de 1683, como el del Censo de Ensenada hace algunos años y el del Vecindario de la Sal después, nos permita seguir removiendo las aguas del debate sobre la historia de la población española en la Edad Moderna.

\section{FUENTES}

Archivo General de Simancas (AGS)

Contadurías Generales, legajo 3186.

Contaduría Mayor de Cuentas (CMC), 3 a época, legajo 3.192.

Consejo y Juntas de Hacienda (CJH), legajos 1443-1511.

Dirección General del Tesoro, Inventario 24, legajos 1381 y 1464.

Biblioteca de la Real Academia de la Historia (BRAH), Signaturas 9/6287 a 9/6330 y 9/ 6338, 9/6340, 9/6342 а 9/6349, 9/6358 a 9/6359, у 9/ 5506, 


\section{BIBLIOGRAFÍA}

Anes, G. (1988): Economía y Sociedad en la Asturias del Antiguo Régimen. Barcelona: Ariel. Bilbao, L. M. (1999): «Estructura y dimensiones de la familia. La familia rural alavesa (1570-1706)», en A. Carreras (ed.), Doctor Jordi Nadal. La industrialización y el desarrollo económico de España. Barcelona: Universidad de Barcelona, vol. II, pp. 27889.

Blanco Carrasco, J. P. (1999): Demografía, familia y sociedad en la Extremadura moderna, 1500-1860. Cáceres: Universidad de Extremadura.

Bustelo, F. (1972): «Algunas reflexiones sobre la población española de principios del siglo XVIII». Anales de Economía 15, pp. 89-106

- (1989): «El vecindario de Campoflorido y la población española del siglo XVII». Revista de Historia Económica VII (2), pp. 297-322.

Bustos Rodríguez, M. et al. (1990): «La población de la provincia de Cádiz en los siglos XVII y XVIII». Trocadero 2, pp. 5-71.

Calonge Matallanes, Ma P., García Zarza, E. y Rodríguez Sánchez, Ma E. (1967): La España del Antiguo Régimen. Estudios históricos editados por Miguel Artola. Fasc. III. Castilla la Vieja. Salamanca: Universidad de Salamanca.

Carbajo Isla, M. F. (1987): La población de la villa de Madrid. Desde finales del siglo XVI hasta mediados del siglo XIX. Madrid: Siglo XXI.

Censo de Castilla de 1591 (1984): Instituto Nacional de Estadística: Madrid.

Censo de Población de la Corona de Castilla «Marqués de la Ensenada» 1752 (1981): Instituto Nacional de Estadística: Madrid.

Coronas TEJADA, L. (s.f.): Estudio demográfico de la ciudad de Jaén en el siglo XVII. Jaén: Cámara Oficial de Comercio e Industria de la Provincia de Jaén.

- (1978): «Estudio demográfico de la ciudad de Jaén en el siglo XVII», en Actas del I Congreso de Historia de Andalucía. Andalucía Moderna (siglos XVI-XVII). Córdoba: Caja de Ahorros y Monte de Piedad de Córdoba, vol. I, pp. 215-31.

CREMAdes Griñán, M ${ }^{a}$ C. (1978-1979): «Evolución demográfica de Alcantarilla». Anales de la Universidad de Murcia. Filosofía y Letras XXXVII (3), pp. 211-266.

Chacón Jiménez, F. (1986): Los murcianos del siglo XVII. Evolución, familia y trabajo. Murcia: Editora Regional de Murcia.

Chacón Jiménez, F. y GonzÁlez Ortiz, J. L. (1978-1979): «Bases para el estudio del comportamiento demográfico de Cehegín, Caravaca y Moratalla en la larga duración (1468-1930)». Anales de la Universidad de Murcia. Filosofía y Letras XXXVII (1-2), pp. 59-90.

Domínguez Ortiz, A. (1981): «La población de la Baja Andalucía», en A. Domínguez Ortiz (dir.), Historia de Andalucía. VI. Los inicios del capitalismo (1621-1778). Barcelona: Planeta, pp. 129-52.

- (1992[1963]): La sociedad española en el siglo XVII. Madrid: CSIC.

Eiras Roel, A. (1996): La población de Galicia, 1700-1860. Crecimiento, distribución espacial y estructura de la población de Galicia en los siglos XVIII y XIX. Santiago de Compostela: Caixa Galicia.

EsPINOSA NúÑEZ, I. (1984): «Estudio demográfico de Albacete y Chinchilla en los años 16731714», en Congreso de Historia de Albacete. III. Edad Moderna. Albacete: Instituto de Estudios Albacetenses/CSIC/Confederación Española de Centros de Estudios Locales, pp. 153-78. 
FERNÁNDEz CoRTizo, C. (1990): «La población de Galicia en la primera mitad del siglo XVII: los vecindarios de 1631 y 1651», en Obradoiro de Historia Moderna. Santiago de Compostela: Universidad de Santiago de Compostela, pp. 103-30.

Fernández OchoA, M. A. (1995): Luarca y la Tierra de Valdés, 1650-1830. Población, Sociedad y Economía. Oviedo: Ayuntamiento de Valdés.

FERnÁndez VARgAS, V. (1996): «La población española en el siglo XVII», en Historia de España Menéndez Pidal. Tomo XXIII. La crisis del siglo XVII. La Población. La Economía. La Sociedad. Madrid: Espasa Calpe, pp. 1-156.

Fortea Pérez, J. I. (1978): «La evolución demográfica de Córdoba en los siglos XVI y XVII», en Actas del I Congreso de Historia de Andalucía. Andalucía Moderna (siglos XVI-XVII). Córdoba: Caja de Ahorros y Monte de Piedad de Córdoba, vol. I, pp. 371-96.

- (1980): Córdoba en el siglo XVI: las bases demográficas y económicas de una expansión urbana. Córdoba: Caja de Ahorros y Monte de Piedad de Córdoba.

García Jiménez, B. (1987): Demografía rural andaluza: Rute en el Antiguo Régimen. Córdoba: Excma. Diputación Provincial de Córdoba/Monte de Piedad y Caja de Ahorros de Córdoba.

García Sanz, A. (1977): Desarrollo y crisis del Antiguo Régimen en Castilla la Vieja. Economía y Sociedad en tierras de Segovia, 1500-1814. Madrid: Akal.

GonzÁLEz, T. (1829): Censo de la población de las provincias y partidos de la Corona de Castilla en el siglo XVI. Madrid: Imprenta Real.

GonzÁlez Prieto, F. J. (2003): «Fuentes demográficas, evolución y estructura socio profesional de la ciudad de Burgos durante los siglos XVI y XVII». Santander: Universidad de Cantabria. Tesis Doctoral.

Grupo '75 (1977): La economía del Antiguo Régimen. La Renta Nacional de la Corona de Castilla. Madrid: Universidad Autónoma de Madrid.

Gutiérrez Alonso, A. (1989): Estudio sobre la decadencia de Castilla. La ciudad de Valladolid en el siglo XVII. Valladolid: Universidad de Valladolid.

Herrero Martínez de Azcoitia, G. (1961): «La población palentina en los siglos XVI y XVII». Publicaciones de la Institución Tello Téllez de Meneses 21, pp. 1-107

Kamen, H. (1964): «The Decline of Castile: the Last Crisis». Economic History Review XVII (1), pp. 63-76.

- (1981): La España de Carlos II. Barcelona: Crítica.

LANZa García, R. (1991): La población y el crecimiento económico de Cantabria en el Antiguo Régimen. Madrid: Universidad Autónoma de Madrid/Universidad de Cantabria.

LÁzaro Ruiz, M. (1994): La población de la ciudad de Logroño en el Antiguo Régimen (1500-1833). Logroño: Instituto de Estudios Riojanos.

Lemaunier, G. (1985): «El Reino de Murcia en el siglo XVIII: realidad y contradicciones del crecimiento», en R. Fernández (ed.), España en el siglo XVIII. Homenaje a Pierre Vilar. Barcelona: Crítica, pp. 289-341.

Livi Bacci, M. (1968): «Fertility and Nuptiality Changes in Spain from the Late 18th to the Early 20th Century». Population Studies XXII (1), pp. 83-102, y (2), pp. 211-34.

López-SAlazar, J. (1976): «Evolución demográfica de La Mancha en el siglo XVIII». Hispania 133, pp. 233-99.

- (1980): «Estructuras agrarias y sociedad rural en La Mancha en los siglos XVI y XVII». Madrid: Universidad Complutense de Madrid. Tesis Doctoral. 
- (1981): «La población manchega en los siglos XVI y XVII». Revista Internacional de Sociología 37, pp. 7-31, y 38, pp. 193-231.

Llopis AgeLÁn, E. (2002): «Expansión, reformismo y obstáculos al crecimiento (1715-1789)», en F. Comín, M. Hernández y E. Llopis (eds.), Historia Económica de España, siglos $X-X X$. Barcelona: Crítica, pp. 121-64.

Llopis Agelán, E. et al. (1990): «El movimiento de la población extremeña durante el Antiguo Régimen». Revista de Historia Económica VIII (2), pp. 419-64.

Llopis Agelán, E. y Pérez Moreda, V. (2003): «Evolución demográfica de la zona centro de España a través de los índices de bautismos, 1580-1850», en Estudios de Historia y de Pensamiento Económico. Homenaje al profesor Francisco Bustelo García del Real. Madrid: Universidad Complutense de Madrid, pp. 113-46.

Marcos GonzÁlez, Ma D. (1971): La España del Antiguo Régimen. Estudios históricos editados por Miguel Artola. Fasc. VI. Castilla la Nueva y Extremadura. Salamanca: Universidad de Salamanca.

Marcos Martín, A. (1978): Auge y declive de un núcleo mercantil y financiero de Castilla al Vieja. Evolución demográfica de Medina del Campo durante los siglos XVI y XVII. Valladolid: Universidad de Valladolid.

- (1988): «Los estudios de demografía histórica en Castilla la Vieja y León (siglos XIVXIX). Problemas y resultados», en V. Pérez Moreda y D.S. Reher (eds.), Demografía histórica en España. Madrid: Ediciones El Arquero, pp. 247-68.

- (2000): España en los siglos XVI, XVII y XVIII. Economía y Sociedad. Barcelona: Crítica/Caja Duero.

Martín Galán, M. (1985): «Nuevos datos sobre un viejo problema: el coeficiente de conversión de vecinos en habitantes». Revista Internacional de Sociología 43 (4), pp. 593-633.

Mateos, M ${ }^{a}$ D. (1966): La España del Antiguo Régimen. Estudios históricos editados por Miguel Artola. Fasc. 0. Salamanca. Salamanca: Universidad de Salamanca.

Maza Zorrilla, E. (1979): «Régimen demográfico de una villa castellana. La natalidad en Villalón de Campos durante los siglos XVI y XVII». Investigaciones Históricas 1, pp. 69-97.

Molina Martínez, J. M. (2004): De propios y extraños. La población de Cádiz en el siglo XVIII. Cádiz: Universidad de Cádiz.

Montaño Requena, Ma I. (1987): «La población de Carmona en las series parroquiales: siglos XVI-XIX». Archivo Hispalense 183, pp. 93-111.

Nadal, J. (1984): La población española (Siglos XVI a XX). Barcelona: Ariel.

Pérez Álvarez, M. J. (1996): La montaña noroccidental leonesa en la Edad Moderna. León: Universidad de León.

Pérez García, J. M. (1988): «Economía y sociedad», en A. Domínguez Ortiz (dir.), Historia de España. 6. La crisis del siglo XVII. Barcelona: Planeta, pp. 175-333.

- (1995): «La evolución de la población andaluza en la Edad Moderna», en Actas del II Congreso de Historia de Andalucía. Andalucía Moderna (I). Córdoba: Junta de Andalucía/ Cajasur, pp. 29-47.

Pérez MoredA, V. (1980): Las crisis de mortalidad en la España interior. Siglos XVI-XIX. Madrid: Siglo XXI.

— (1997): «La evolución demográfica», en L. De Rosa y L.M. Enciso Recio (eds.), Spagna e Mezzogiorno d'Italia nell'etá della transizione. Nápoles: Edizione Scientifiche Italiane, vol. 2, pp. 139-59. 
Pèrez Moreda, V. y Reher, D. S., (1986): «Mecanismos demográficos y oscilaciones a largo plazo de la población europea (1200-1850)». Revista de Historia Económica IV (3), pp. 467-92.

Piquero Zarauz, S. (1991): Demografía guipuzcoana en el Antiguo Régimen. Bilbao: Universidad del País Vasco.

Piquero, S., PJeda, R. y Fernández de Pinedo, E. (1991): «El Vecindario de 1631: presentación y primeros resultados», en J. Nadal (coord.), La evolución demográfica bajo los Austrias. Alicante: Instituto de Cultura Juan Gil-Albert, pp. 77-89.

Ponsot, P. (1986): Atlas de Historia Económica de Andalucía. (Siglos XVI-XIX). Sevilla: Editoriales Andaluzas Reunidas.

Reher, D.S. (1990): Town and Country in Pre-industrial Spain. Cambridge: Cambridge University Press.

- (1991): «Dinámicas demográficas en Castilla la Nueva, 1550-1900: un ensayo de reconstrucción», en J. Nadal (coord.), La evolución demográfica bajo los Austrias. Alicante: Instituto de Cultura Juan Gil-Albert, pp. 17-75.

RodríGuez Alemán, I. (2003): La población de Málaga en el siglo XVII. Málaga: Centro de Ediciones de la Diputación de Málaga.

Rodríguez Grajera, A. (1990): La Alta Extremadura en el siglo XVII. Evolución demográfica y estructura agraria. Cáceres: Universidad de Extremadura.

Rubio Pérez, L.M. (1987): La Bañeza y su tierra, 1650-1850. León: Universidad de León.

Rueda Fernández, J. C. (1989): «Demografía y comportamientos en la Zamora de los siglos XVI y XVII». Salamanca: Universidad de Salamanca. Tesis Doctoral.

SaAvedra, P. (1985): Economía, Política y Sociedad en Galicia: La provincia de Mondoñedo, 1480-1830. Madrid: Xunta de Galicia.

— (1996): «As grandes tendencias comarcais na evolución da poboación galega (de comezos do XVII a mediados do XIX)», en Das casas de morada ó monte comunal. Vigo: Xunta de Galicia, pp. 77-146.

SÁnchez BelÉn, J. A. (1989): «Absolutismo y fiscalidad en Castilla a fines del siglo XVII: el encabezamiento general del reino (1682-1685)». Espacio, Tiempo y Forma, Serie IV, Historia Moderna 2, pp. 175-218.

- (1996): La política fiscal en Castilla durante el reinado de Carlos II. Madrid: Siglo XXI.

SÁncheZ-MonTes, F. (1989): La población granadina del siglo XVII. Granada: Universidad de Granada.

SANCHO AlguACIL, R. (1987): «Población y estructura familiar en una comunidad de la vega alta del Segura: Cieza durante el siglo XVIII», en Chacón, F. (ed.), Familia y sociedad en el Mediterráneo occidental. Siglos XV-XIX. Murcia: Universidad de Murcia, pp. 279-99.

ToRres SÁnchez, R. (1998): Ciudad y población. El desarrollo demográfico de Cartagena durante la Edad Moderna. Murcia: Ayuntamiento de Cartagena/Real Academia Alfonso $\mathrm{X}$ El Sabio.

VAlle Buenestado, B. (1978): «Notas sobre la evolución demográfica de la comarca de Los Pedroches (1530-1857)», en Actas del I Congreso de Historia de Andalucía. Andalucía Moderna (siglos XVI-XVII). Córdoba: Caja de Ahorros y Monte de Piedad de Córdoba, I, pp. 289-305.

Vincent, B. (1981): «Economía y sociedad en el Reino de Granada (Siglo XVII)», en A. Domínguez Ortiz (dir.): Historia de Andalucía. VI. Los inicios del capitalismo (16211778). Barcelona: Planeta, pp. 353-72. 
EL VECINDARIO DE 1683: UNA FUENTE INÉDITA PARA EL ESTUDIO DE LA POBLACIÓN...

Yun, B. (1987): Sobre la transición al capitalismo. Economía y Sociedad en Tierra de Campos (1500-1830). Salamanca: Junta de Castilla y León.

- (1999): «Del centro a la periferia: la economía española bajo Carlos II». Studia Historica. Historia Moderna 20, pp. 45-75. 
